\title{
THE LIVED EXPERIENCE OF FATHERS WHO HAVE CHILDREN WITH ASTHMA: A PHENOMENOLOGICAL STUDY
}

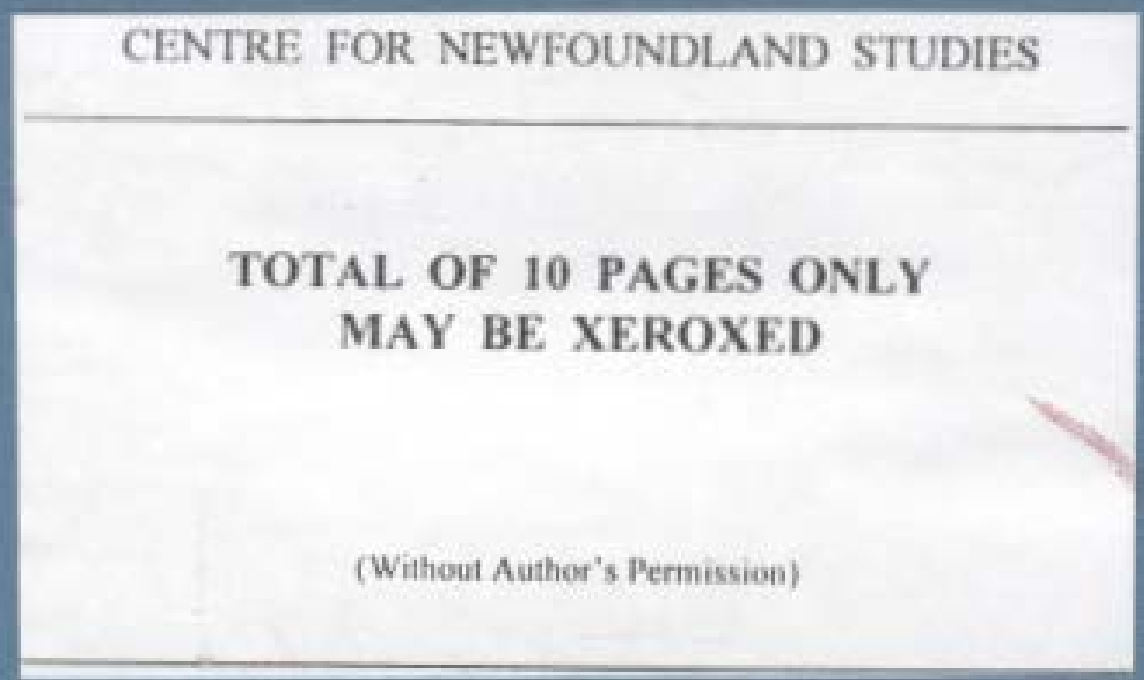

\section{GERALDINE H. CASHIN}







$\begin{array}{ll}\begin{array}{l}\text { National Library } \\ \text { of Canada }\end{array} & \begin{array}{l}\text { Bibliothèque nationale } \\ \text { du Canada }\end{array} \\ \begin{array}{l}\text { Acquisitions and } \\ \text { Bibliographic Services }\end{array} & \begin{array}{l}\text { Acquisisitons et } \\ \text { services bibliographiques }\end{array} \\ \begin{array}{l}\text { 395 Wellington Street } \\ \text { Ottawa ON K1A 0N4 } \\ \text { Canada }\end{array} & \begin{array}{l}\text { 395, rue Wellington } \\ \text { Ottawa ON K1A ON4 } \\ \text { Canada }\end{array}\end{array}$

Your file Votre référence

ISBN: 0-612-93017-3

Ourfile Notre référence

ISBN: 0-612-93017-3

The author has granted a nonexclusive licence allowing the National Library of Canada to reproduce, loan, distribute or sell copies of this thesis in microform, paper or electronic formats.

The author retains ownership of the copyright in this thesis. Neither the thesis nor substantial extracts from it may be printed or otherwise reproduced without the author's permission.
L'auteur a accordé une licence non exclusive permettant à la Bibliothèque nationale du Canada de reproduire, prêter, distribuer ou vendre des copies de cette thèse sous la forme de microfiche/film, de reproduction sur papier ou sur format électronique.

L'auteur conserve la propriété du droit d'auteur qui protège cette thèse. $\mathrm{Ni}$ la thèse ni des extraits substantiels de celle-ci ne doivent être imprimés ou aturement reproduits sans son autorisation.
In compliance with the Canadian

Privacy Act some supporting forms may have been removed from this dissertation.

While these forms may be included in the document page count, their removal does not represent any loss of content from the dissertation.
Conformément à la loi canadienne sur la protection de la vie privée, quelques formulaires secondaires ont été enlevés de ce manuscrit.

Bien que ces formulaires aient inclus dans la pagination, il n'y aura aucun contenu manquant. 

The Lived Experience Of Fathers Who Have Children With Asthma:

A Phenomenological Study

by

Geraldine H. Cashin, B.N., R.N.

\author{
A thesis submitted to the \\ School of Graduate Studies \\ in partial fulfillment of the \\ requirements for the degree of \\ Master of Nursing \\ School of Nursing \\ Memorial University of Newfoundland
}

September 2003

St. John's

Newfoundland \& Labrador 


\begin{abstract}
Asthma is the most common chronic illness of childhood. It is a leading cause of school absenteeism and accounts for a major portion of pediatric admissions to emergency departments and hospitals. When a child is diagnosed with asthma, parents become responsible for the long-term management of a chronic condition that may be characterized by unpredictable and irregular episodes.

Most of the research concerning parents and childhood asthma is focussed on mothers. The small number of studies in which mothers and fathers were compared revealed that differences do exist between their experiences and responses. Paternal perspectives and experiences of caring for a child with asthma have been sparsely explored.

This phenomenological study used van Manen's (1994) method of inquiry to explore the lived experience of fathers who have children with asthma. A sample of eight fathers with children aged 7 to 11 years who had been diagnosed with asthma were interviewed in order to find out what their experiences were like. From the analysis of the interview data, five themes were identified: feeling relief in knowing the diagnosis, learning the ropes, living with concern, being vigilant, and being comfortable with asthma management. The findings from this study have implications for nursing practice, education, and research. Understanding the experience of fathers who have children with asthma, and gaining insight into their needs and concerns is a first step to providing supportive nursing care. It is important to include fathers in future research studies and examine their unique experience in parenting ill children.
\end{abstract}




\section{ACKNOWLEDGEMENTS}

I would like to extend my appreciation to the fathers who participated in this study and willingly gave their time to share their experiences with me.

A sincere thank you to my thesis supervisor, Professor Sandra Small, for her guidance, insight, availability, and patience during the completion of this study. Thank you to Dr. Shirley Solberg who provided valuable feedback and guidance.

Thank you to Ms. Marion Clarke, Nurse Coordinator, Asthma Program, Janeway Child Health Centre, for contacting the participants and asking them to participate in this study.

I am grateful to my colleagues at the Centre for Nursing Studies and to Mrs. Joan Rowsell, Director of the Centre for Nursing Studies, for their support and encouragement as I completed this study.

Thank you to my children, Megan and Brendan, who assumed extra roles so I could devote my time to completing my program of study. A very special thank you to my partner, Doug, whose support, encouragement, and immense patience helped me in so many ways.

I also would like to acknowledge the financial support that I received from the Association of Registered Nurses of Newfoundland and Labrador, the Canadian Nurses' Respiratory Society, and the Janeway Children's Hospital Foundation. The research grants I received helped defray the expenses incurred in the completion of this study. 


\section{Table of Contents}

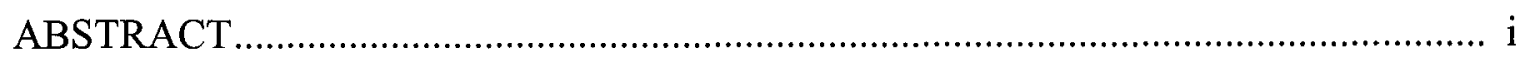

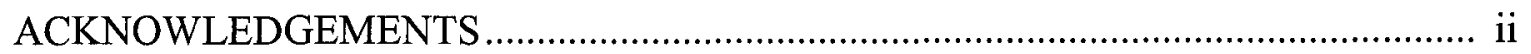

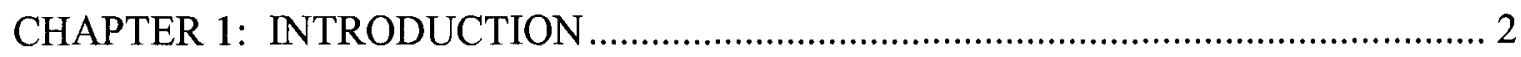

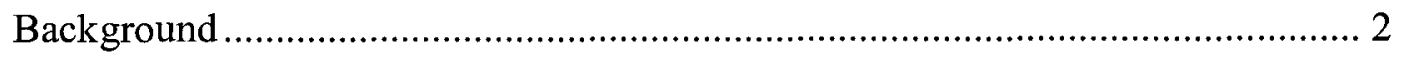

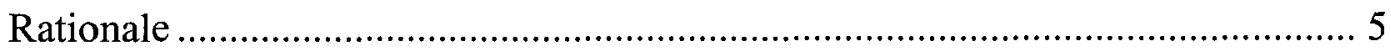

Purpose

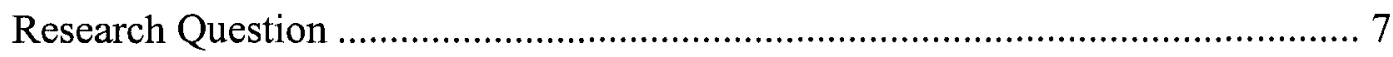

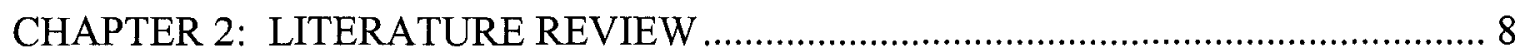

The Impact of Childhood Asthma on Parents....................................................... 8

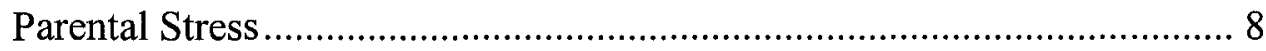

Sources of Parental Stress............................................................ 9

Parental worry and concerns about the illness and its management .................................................................... 9

Demands of Caregiving ....................................................10

Parental Experiences with Childhood Asthma …………............................15

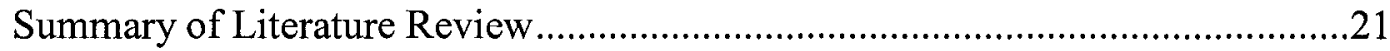

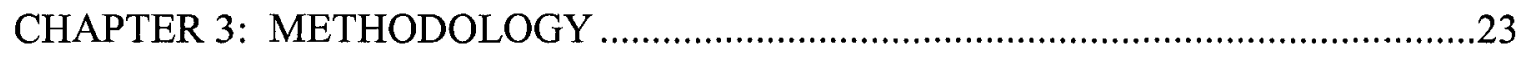

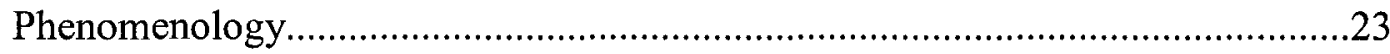

Procedure for Recruitment of Participants...........................................................32

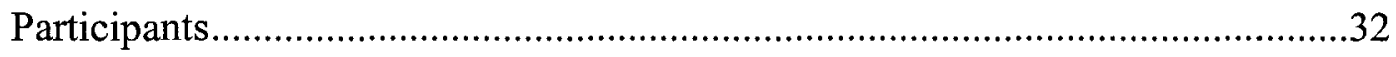

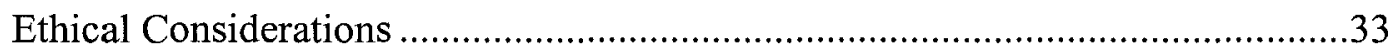

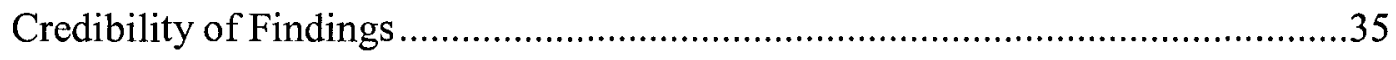




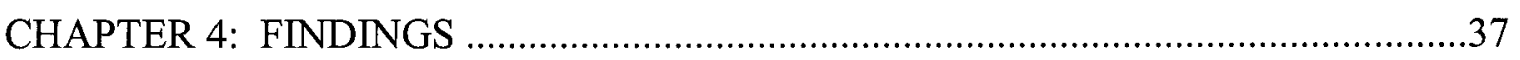

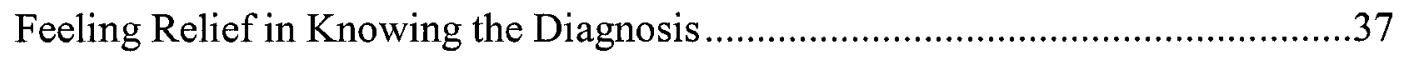

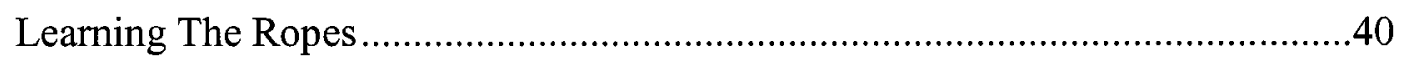

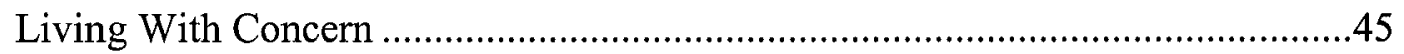

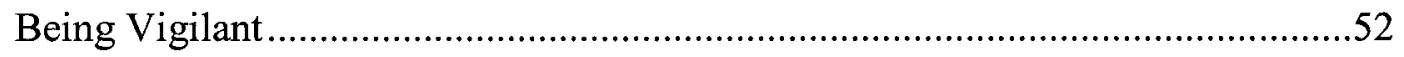

Being Comfortable With Asthma Management …………...................................55

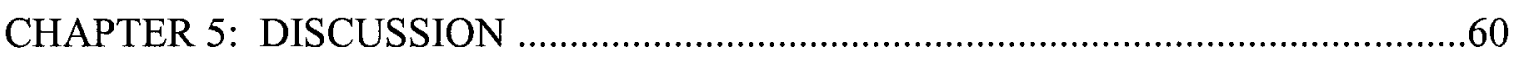

Feeling Relief in Knowing the Diagnosis..........................................................6

Learning The Ropes ........................................................................................61

Living With Concern .........................................................................................64

Being Vigilant .....................................................................................................66

Being Comfortable With Asthma Management ....................................................67

CHAPTER 6: IMPLICATIONS AND SUMMARY ……………….............................73

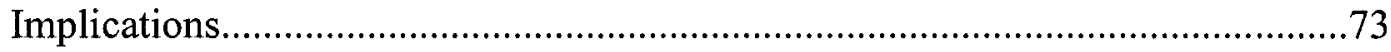

Nursing Practice ......................................................................................

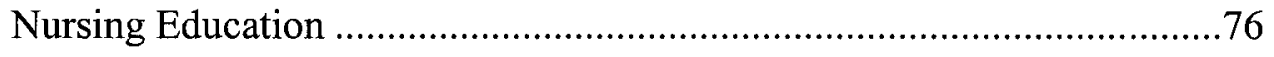

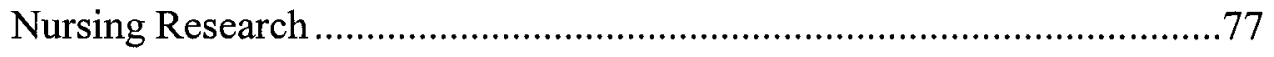

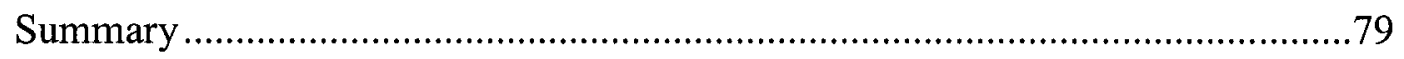

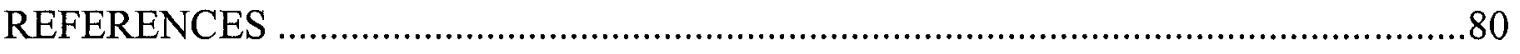

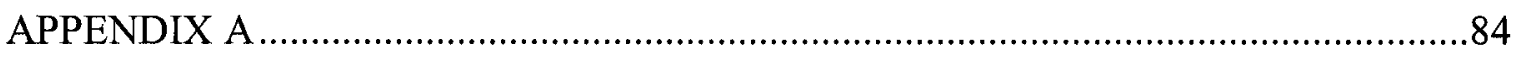

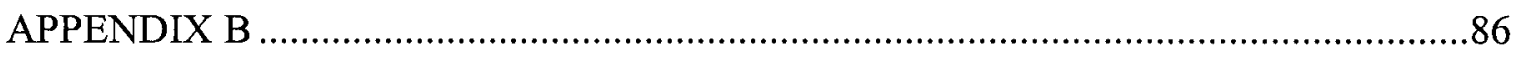

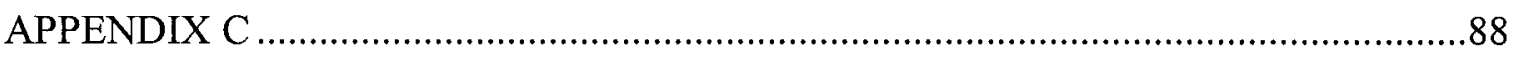

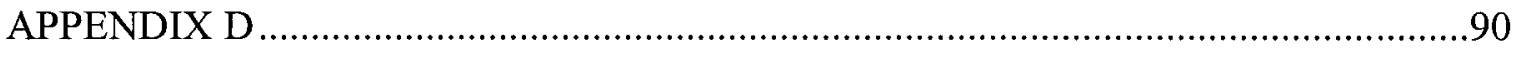

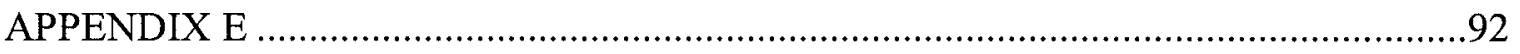




\section{CHAPTER 1}

\section{BACKGROUND}

Asthma is the most common chronic illness of childhood (American Lung Association [ALA], 2003; Canadian Lung Association [CLA], 2003). It is an inflammatory disorder of the airways that is characterized by airway hyperresponsiveness to a variety of stimuli and by variable airflow limitation. The exact etiology of asthma is unknown; however, there is general agreement that airway inflammation is the pathological mechanism. The chronic inflammation causes bronchospasm, mucosal edema, and increased mucous production in the hypersensitive airways of susceptible individuals. The airway changes are responsible for the obstructive symptoms found in asthma, including dyspnea, chest tightness, wheezing, sputum production, and cough. Symptomatic episodes are recurrent in response to exposure to agents (known as triggers) such as allergens, environmental irritants, viral infections, cold air, and exercise. Individuals may have different triggers and their triggers may vary over time (Canadian Asthma Consensus Group, 1999; The National Asthma Task Force, 2000).

Asthma may vary greatly from one child to another in terms of the frequency and severity of symptoms. Some children with asthma may be predominantly symptom-free, with just occasional symptomatic episodes. An asthma episode, which is often called an asthma attack, may begin suddenly or may come on slowly with gradually worsening symptoms following exposure to a trigger, such as exercise. It lasts for a short period, from minutes to hours. Most attacks are managed by giving medications that relieve the acute symptoms. Other children may be symptomatic most of the time and have acute exacerbations after exposure to certain asthma triggers, such as respiratory infection. An 
acute exacerbation may last from days to weeks and requires medication adjustment to bring the asthma back under control. At diagnosis, the severity of asthma in a patient is determined by the frequency and duration of respiratory symptoms, and the degree of airflow limitation as indicated by objective diagnostic measures. Once asthma is controlled, the level of asthma severity is determined by the type of treatment needed to maintain control. There are five levels of asthma severity, ranging from very mild to very severe (Canadian Asthma Consensus Group, 1999).

The main thrust of asthma management is to decrease airway inflammation by reducing or eliminating exposure to triggers and using anti-inflammatory medications, generally inhaled corticosteroids. Bronchodilating medications are used as needed to relieve acute asthma symptoms (Canadian Asthma Consensus Group, 1999). According to the report from The National Asthma Control Task Force (2000), effective management of asthma should include: (a) patient education about asthma and its management; (b) avoidance or control of triggers; (c) individualized medication regime; (d) medical monitoring and follow-up in relation to symptom control, medication effectiveness, and lung function; and (e) a personalized self-management plan.

Childhood asthma has increased in many industrialized nations over the past two decades, with the estimated prevalence being from 4 to $30 \%$ in different countries (Millar \& Hill, 1998; National Institutes of Health, 2002). Factors hypothesized as contributing to the increased prevalence are: tighter homes resulting in decreased ventilation and trapping of indoor air pollutants and allergens; greater use in homes of products with off-gassing, such as carpets and man-made wood materials; increased outdoor air pollution; and increased use of processed foods which contain potential 
allergens, such as dyes and preservatives. Also, it is suggested that perhaps some of the increase in prevalence may be due to changes in the definition of the condition, with asthma being more clearly distinguished from other chronic respiratory conditions, enabling a more accurate diagnosis of asthma using objective measures (The National Asthma Control Task Force, 2000). Approximately $11 \%$ of Canadian children have been diagnosed with asthma (Statistics Canada, 1999). Asthma is a major cause of school absenteeism (CLA, 2003) and is the leading cause of hospitalization for children (Conners \& Millar, 1999; Health Canada, 2001).

A chronic illness with an episodic course, such as asthma, requires that family members must constantly adjust themselves to the consequences of the disease (Newby, 1996). Thus, when a child is diagnosed with asthma, the entire family experiences life with the illness. Parents become responsible for the long-term management of a chronic condition that is characterized by unpredictable and irregular symptomatic episodes. Studies concerning parents of children with asthma have revealed that parents experience stress as a result of their children's asthma (Bussing \& Burkett, 1993; Eiser, Eiser, Town, \& Tripp, 1991; Hamlett, Pellegrini, \& Katz, 1992; Kieckhefer \& Ratcliffe, 2000; Kurnat \& Moore, 1999; Mailick, Holden, \& Walther, 1994). Being the parents of a child with asthma was described as a difficult situation which involved a variety of feelings (Englund, Rydstrom, \& Norberg, 2001). Parents experienced worry, anxiety, and uncertainty about the illness and its management (Donnelly, 1994; Kieckhefer \& Ratcliffe; MacDonald, 1996; Peri, Molinari, \& Taverna, 1991; Staudenmayer, 1981; Whyte, Baggaley, \& Rutter, 1995) and found caregiving to be demanding (Barrett, Gallien, Dunkin, \& Ryan, 2001; Brown, Avery, Mobley, Boccuti, \& Golbach, 1996; 
Donnelly; Eiser et al.; Peri et al.; Kurnat \& Moore; Mailick et al.; Wasilewski et al., 1988). In addition, parents described a variety of concerns in relation to having a child with asthma (Barrett et al.; Kurnat \& Moore; Kieckhefer \& Ratcliffe; Syndor-Greenberg \& Dokken, 2000; Whyte et al.).

A number of studies have described a process that parents went through as they learned to gain control of the asthma and integrate it into family life (Horner, 1998; Clark \& Chalmers, 2003; Jerrett \& Costello, 1996). The findings from those studies suggested that incorporating asthma management was a process lived over time, and highlighted the importance of informational and social support to the parents' adjustment. Other researchers found that family strengths (Svavarsdottir, McCubbin, \& Kane, 2000) and asthma education (Canadian Asthma Consensus Group, 2001; Colland, 1993; Deaves, 1993; McCarthy et al., 2002) had a positive influence on caregiving demands as perceived by parents.

\section{RATIONALE}

Although there is a growing body of knowledge concerning parents and childhood asthma, much of the research is actually about mothers. Many studies were focussed exclusively on mothers. Others had a greater proportion of mothers than fathers and the findings were reported from pooled data. Thus, the paternal perspective of caring for a child with asthma has been relatively unexplored. The same trend has been noted in the vast body of literature concerning parents and childhood chronic illness, in general, in that much of the research is about mothers. The focus on mothers may have occurred because mothers traditionally have been the primary caregivers. Mothers often did not work outside of the home and were available to bring their children to the health center or 
clinic. They, therefore, were more available to participate in research (Graves, 1997). However, current literature indicated that fathers are taking a more active role in the care of their children (May, 1996; Tiedje \& Darling-Fisher, 1996). In many families, childcare has become a shared responsibility. In my clinical practice, I have noted that fathers are a visible presence in all pediatric clinical settings and are involved in the care of their chronically ill children.

One cannot generalize from maternal to paternal experiences in pediatric chronic illness. In the studies that compared maternal and paternal experiences with childhood asthma, some differences were noted with respect to their perceptions of the caregiving experience (Englund et al., 2001; Svavarsdottir et al., 2000). In order to provide effective nursing care, nurses need to have an understanding of fathers' perceptions of their situation. With more fathers undertaking and sharing the primary caregiving role for their children, a greater understanding of their experience is important. Little is known about the father's perspective in having a child with asthma.

\section{PURPOSE}

An individual's own experience is a necessary starting point for any scientific inquiry (Speziale \& Carpenter, 2003). Since it was apparent from the literature review that there was limited information from the paternal perspective, it was appropriate that a qualitative study be undertaken to explore the experience of fathers who have children with asthma. The purpose was to develop a greater understanding of what it is like to be the father of a child with asthma, thus contributing to the body of knowledge related to parents who have a child with asthma and adding new knowledge in relation to the paternal experience. Understanding their experience lays the groundwork for future 
studies of nursing interventions to assist fathers in adjusting to having a child with asthma.

\section{RESEARCH QUESTION}

The research question addressed in this study was: What does it mean to be the father of a child with asthma? 


\section{CHAPTER 2}

\section{LITERATURE REVIEW}

Asthma, like other childhood chronic illnesses, affects many aspects of family life. Accordingly, much of the research literature concerning parents and childhood asthma is related to the impact of the asthma on the parents. Although researchers have examined how parents' lives are affected by the child's illness, no studies were found that focussed specifically on fathers of children with asthma. In some of the studies, fathers were included in the study group but the research was largely about mothers. Therefore, this literature review, by necessity, is comprised of studies that pertain to parents, rather than to fathers as a separate group.

\section{The Impact of Childhood Asthma on Parents}

The predominant focus of research concerning parents and childhood asthma is related to the impact of the asthma on parents. In particular, studies are focussed on parental stress and parental experiences with childhood asthma. This section provides a discussion of the literature that addresses those areas of research.

\section{Parental Stress}

That parents of children with asthma experience stress in their lives due to the presence of the illness in their children is well supported in the literature (e.g., Kieckhefer \& Ratcliffe, 2000; Kurnat \& Moore, 1999; Mailick et al., 1994). Parents of children with asthma have been found to have higher levels of stress than parents of healthy children and parents of children with other chronic conditions. Eiser et al. (1991) conducted a study in which parents of children with asthma and parents of healthy children were interviewed about the everyday care of their children. The parents of children with 
asthma reported experiencing greater stress from everyday, routine occurrences and activities, compared with the parents of healthy children. In a study of chronic illness as a family stressor, Hamlett et al. (1992) interviewed mothers of children with asthma, mothers of children with diabetes, and a control group of mothers with healthy children. The mothers of children with asthma reported a greater number of stressful events related to the care of their children than did the mothers of children with diabetes or the mothers in the control group. Similarly, Bussing and Burkett (1993) found that parents of children with asthma had higher levels of stress than parents of children with hemophilia and parents of healthy children.

\section{Sources of Parental Stress}

The sources of the stress experienced by the parents of children with asthma may be broadly categorized as worry and concerns about the illness and illness management, and demands of caregiving.

Parental worry and concerns about the illness and its management. In an early study of the effects of childhood asthma on parents, Staudenmayer (1981) found that parents were worried about their children's illness and this often resulted in anxiety and distress for them. The study indicated that parental anxiety was highly correlated with the extent of debilitation experienced by the child, as measured by the number of asthma attacks, the number of emergency room visits, the number of hospitalizations, school absenteeism, and interference in the child's daily activities. Similarly, Peri et al. (1991) noted a predominant feeling of anxiety among parents of children with asthma that was brought about by the mere presence of the disease in the child, by exacerbations of the disease, and by the chronic nature of the disease. Further, parents of children with asthma 
have felt stress because of the unpredictability of exacerbations of the condition (Donnelly, 1994).

A number of researchers have examined concerns of parents in relation to having children with asthma. Parents have reported having concern about: their ability to manage the asthma and treat exacerbations (Kieckhefer \& Ratcliffe, 2000; Whyte et al., 1995); their children's tendency not to want to co-operate with prescribed treatments (Kurnat \& Moore, 1999; Whyte et al.); restrictive school medication policies that prevent children from carrying their inhalers with them (Barrett et al., 2001); the effect of the asthma on their children's self-esteem (Kurnat \& Moore; Syndor-Greenberg \& Dokken, 2000); their children's ability to manage the asthma on their own when they are older (SyndorGreenberg \& Dokken); the potential adverse effects of the medications, in particular inhaled steroids (Kieckhefer \& Ratcliffe; Syndor-Greenberg \& Dokken); and their children's future health and the long-term consequences of asthma (Syndor-Greenberg \& Dokken; Whyte et al.). The uncertainty with respect to their children's future health has been identified by parents as one of their main concerns (Keickhefer \& Ratcliffe; Whyte et al.).

Demands of caregiving. Asthma is a chronic condition, the management of which can require considerable parental effort over a long period of time. Parents of children with asthma have reported experiencing stress in relation to caregiving. The demands of caregiving for a child with asthma can disrupt day-to-day living (Barrett et al., 2001; Brown et al., 1996; Donnelly, 1994; Eiser et al., 1991; Peri et al., 1991;Wasilewski et al., 1988 ) and have a negative impact on parents' physical and social functioning, and 
financial resources (e.g., Barrett et al.; Brown et al.; Donnelly; Kurnat \& Moore, 1999; Mailick et al., 1994).

Wasilewski et al. (1988) examined the disruption to daily life that mothers experienced due to childhood asthma. Disruption was defined as "the burdens that asthma imposes on the daily lives of the mothers" (p. 37). The most common disruptions identified by the mothers were interrupted sleep, interrupted work schedules and social activity, additional housework to maintain an allergen-free environment, the need to administer medications and monitor symptoms, and the need to provide emotional support to the child during symptomatic periods. Donnelly (1994) reported that parents of children with asthma experienced disruption in their lives because of the unpredictable nature of asthma episodes and that they felt stress in relation to the disruption. Eiser et al. (1991) found that parents of children with asthma experienced disruption in everyday routine activities, such as shopping with their children and settling them for bed.

Not only may parents' lives be disrupted as a result of caring for a child with asthma but also family life, in general, may be disrupted and relationships within the family may be negatively affected. Mothers of young children with asthma reported that asthma disrupted daily life by interfering with activities such as family outings and other family events. Activities sometimes had to be cancelled because the child had asthma symptoms or an asthma attack (Brown et al., 1996). Other parents also have reported that family activities had to revolve around their children's illness (Peri et al., 1991). They acknowledged that, sometimes, such disruption caused them to experience feelings of resentment towards their sick child. As well, sometimes disagreements occurred between them and their spouses over how they should intervene when the child was ill. They 
described such disagreements as one of the most disturbing elements of the illness situation for them. In another study, parents described difficulty in gaining the cooperation of family members with environmental controls while, at the same time, maintaining good family relationships. The most troublesome issues that parents experienced were with respect to conflicts about family pets and exposure to smoking in relatives' homes (Barrett et al., 2001).

In some studies, caring for a child with asthma has been described as having a negative impact on various aspects of caregivers' or parents' functioning. Mailick et al. (1994) studied primary caregivers of children with asthma. Although it is not clear whether the caregivers were mothers, fathers, or some other persons, it is evident that they experienced significant levels of stress because of personal strain, financial burden, and social isolation associated with the child's care. The most negative effect of the child's asthma was the personal strain. The caregivers were fatigued, were unable to plan for the future, and were having difficulty getting reliable help to assist with the child's care when they needed it. Similarly, mothers of young children with asthma have reported that they expended a substantial amount of time and effort in managing their children's asthma (Brown et al., 1996). They described how they had to be responsible for all aspects of their children's asthma care and had to coordinate asthma management with teachers, day care workers, and family members. The mothers experienced difficulty with their own work responsibilities because of the child's asthma management needs and experienced sleepless nights because the child had difficulty sleeping due to symptoms. Eiser et al. (1991) also found that parents of children with asthma experienced interrupted sleep patterns because of being awakened by their ill children at night. 
Mothers and fathers have been shown to differ in their perceptions of caregiving demands. Svavarsdottir et al. (2000) asked parents of young children with asthma to identify the most time-consuming and most difficult caregiving demands associated with their children's care. Although mothers and fathers were alike on what they perceived as the most time-consuming caregiving tasks, they differed on what they considered to be the most difficult tasks. Both reported that the most time-consuming caregiving tasks were providing emotional and developmental support, and managing discipline and behavioral problems. However, fathers ranked their most difficult caregiving tasks, in order of greatest to least priority, as handling an asthma episode, providing emotional support for their spouse or partner, and planning activities for the family. Mothers ranked their most difficult caregiving tasks, in order of greatest to least priority, as managing their own fatigue when caring for the child with asthma, handling an asthma episode, and managing discipline and behavioral problems of the child.

Several factors have been identified in the literature as positive influences on caregiving demands. These may be described as paternal support, family strengths, and parental education in the management of childhood asthma. Wasilewski et al. (1988) hypothesized that paternal involvement in asthma care, as perceived by the mothers, would be associated with less maternal disruption due to the child's asthma. The results of their study indicated that the frequency of paternal involvement in the care of the child's asthma was positively associated with lower maternal disruption. The researchers concluded that it was the father's involvement in the care of the child, rather than the mere presence of the father in the household, that reduced the disruption experienced by the mother. 
Svavarsdottir et al. (2000) found that sense of coherence and family hardiness were predictors of mothers' and fathers' well-being in the caregiving experience. Wellbeing was defined as how the parents felt about their inner personal state.

Parental asthma education long has been considered crucial to childhood asthma management. Not only does it have a positive influence on asthma morbidity (Canadian Asthma Consensus Group, 2001; Deaves, 1993) but also on parents' adaptation to the condition (e.g., Colland, 1993; Deaves). Parents themselves have acknowledged the need and desire for education (Kieckhefer \& Ratcliffe, 2000; Kurnat \& Moore, 1999; SyndorGreenberg \& Dokken, 2000; Whyte et al., 1995) and have reported wanting to be regarded as partners in their children's care (Kieckhefer \& Ratcliffe). Several researchers have examined specific parental outcomes of asthma education. Hanson (1998) determined that parental self-efficacy in managing their children's asthma increased following participation in a basic asthma education program provided by nurse educators. Deaves (1993) found that an asthma program based on the active involvement of parents was successful in improving parental knowledge about asthma and increasing their level of confidence in the management of their children's asthma. McCarthy et al. (2002) noted that an empowering approach to asthma education made a significant difference in parents' sense of control, their ability to make decisions about asthma management, and their ability to provide care for their children. The education program which was examined had content and discussion on establishing parent-professional partnerships, thus emphasizing the active involvement of parents as equal partners in the health care team. 


\section{Parental Experiences with Childhood Asthma}

In several studies, parents' experiences with childhood asthma were examined from a qualitative perspective with exploration of the culture, social process, or essence of the caregiving experience. Because the participants were not restricted to responding to predetermined questions and selecting specific options, the qualitative studies provided rich descriptions of parents' perspectives about childhood asthma. Among the qualitative studies that were identified from the literature search, two focussed exclusively on mothers (Horner, 1997; MacDonald, 1996) and four examined the experiences of mothers and fathers combined (Clark \& Chalmers, 2003; Englund et al. 2001; Horner, 1998; Jerrett \& Costello, 1996). Findings from these studies further support the contention that having a child with asthma is stressful for the parents.

Horner (1997) used grounded theory methodology to examine the experience of mothers of school-aged children with asthma. The mothers described a prediagnosis phase, that is, the period of time prior to the diagnosis of asthma when their children were having episodes of illness. The prediagnosis phase was an uncertain and overwhelming time for the mothers. "Groping in the dark" was identified as the core variable that described the mothers' struggle with uncertainty in relation to the cause of their children's illness episodes. "Unending illness" reflected the mothers' stories of not knowing what was wrong with their children, staying up through the night watching their children struggle to breathe, and feeling worn out because of the disruption in sleep patterns and worry over the child's condition. "Searching for answers" captured the mothers' experiences as they questioned the child's health care providers, tried alternatives to traditional care, and demanded attention by seeking a change in the 
prescribed plan or seeking a referral to a specialist. Once the diagnosis of asthma was established, the mothers reported a sense of relief in knowing what was wrong with their children. The energy that had been expended in the anxiety of the prediagnosis period then was refocussed into learning about asthma management.

MacDonald (1996) also revealed the theme of uncertainty when she conducted an ethnographic study of mothers of children with asthma. Whereas Horner (1997) uncovered uncertainty related to the prediagnosis phase, MacDonald discovered uncertainty in relation to the management of the disease, that is, after the diagnosis of asthma was confirmed. Similar to the mothers in Horner's study, the mothers in MacDonald's study reported feeling relief upon being told that their children had asthma. The diagnosis of asthma alleviated some of their uncertainty because they then knew what was wrong with their children. The mothers in MacDonald's study described their experiences with "mastering uncertainty" in terms of: (a) actions they took and resources they used to increase their knowledge of asthma; (b) changes in themselves whereby they moved from feelings of self-doubt, fear, and frustration to feelings of self-trust, control, and increased self-esteem; and (c) a passage of time marked by the appearance of the child's symptoms, the diagnosis of asthma, the acquisition of knowledge of asthma, and the integration of knowledge and feelings to a point whereby they were able to take control of their situation. The mothers described how they periodically returned to some of their earlier feelings of fear, self-doubt, and frustration, especially when their children had an exacerbation of the asthma. However, over time, the intensity and duration of the emotions were of a lesser degree as the process of "mastering uncertainty" gained 
strength. The mothers' mastery over uncertainty indicated their gradual adjustment to the diagnosis of asthma in their children.

The process of parental adjustment to childhood asthma has been described in other studies. Several researchers used grounded theory methodology to examine the process by which parents adjusted to asthma and, over time, incorporated it into their daily lives (Clark \& Chalmers, 2003; Horner, 1998; Jerrett \& Costello, 1996). Jerrett and Costello identified the core variable of "gaining control". The process that the parents moved through in integrating their children's asthma into their lives may be likened to what MacDonald described as "mastering uncertainty". With the passage of time, the parents in Jerrett and Costello's study experienced three phases: (a) being out of control, which involved seeking medical attention, getting the "run around" until the diagnosis was made, and making sense of the diagnosis; (b) being involved, which was characterized by learning about asthma, trying out new management strategies, and making lifestyle changes to accommodate the child's asthma; and (c) being in control, at which point the parents had transcended the distress associated with asthma management, developed strategies to access information and health care for the child, and felt competent in their ability to meet the demands of their situation. As in Horner's (1997) study, the parents reported that the prediagnosis phase was characterized by uncertainty that made them feel overwhelmed. Horner described the mothers' experience with uncertainty in the prediagnosis period as "groping in the dark". Similarly, Jerrett and Costello referred to the prediagnosis period for the parents as "being out of control". As in both MacDonald's and Horner's studies, the diagnosis of asthma was met with relief because it marked a turning point from a state of uncertainty to a phase whereby they 
could learn to control the child's illness. The parents viewed the availability of health care professionals as a facilitating factor in influencing their successful movement through the various phases and in gaining control of asthma management (Jerrett \& Costello). The ownership of "special knowledge", which they gained from experiential learning, was identified by the parents as important to gaining control and feeling confident in their ability to handle their situation.

Horner (1998) also described parents' experiences in gaining control of their children's asthma. She identified "catching the asthma" as the core variable that reflected parents' descriptions of how they sought to get ahead of, or "catch", the asthma before it got out of hand. The process of "catching the asthma" consisted of: (a) learning about asthma and achieving mastery of the basic tasks of asthma management; (b) becoming proficient at recognizing, preventing, and managing episodes; and (c) coming to terms with asthma by balancing the demands of family life and refocussing energy on other important issues within the family. The children also moved through the phases of "catching the asthma". They moved from relying on others for asthma care to being able to initiate self-medication and behavioral strategies to alleviate asthma symptoms. As they came to terms with asthma, the children were able to assume greater responsibility for asthma care, thus gaining control as well. As proficiency in asthma management grew over time, the meaning of asthma changed for the families. Asthma care moved from the forefront of the family's life and became a part of their daily routine, indicating adjustment over time.

Similar to others (Horner, 1998; Jerrett \& Costello, 1996), Clark and Chalmers (2003) described a process of adjustment, whereby parents learned to integrate their 
children's asthma into their daily lives. The process started with the parents acknowledging and understanding the diagnosis of asthma. They drew on previous family experience with asthma, learned by comparing their children's asthma to that of other relatives, and came to understand the actions they needed to take to manage their own children's asthma. They moved on to gain the knowledge and skills required to manage asthma in a competent manner. They sought out information from various sources and used that knowledge to learn how to recognize, treat, and, eventually, prevent acute episodes. In the final phase of the process, the parents had incorporated asthma care into their daily lives. They were adept at predicting and preventing trigger situations, were comfortable adjusting the medication regime, and felt they had gained some control in managing the disease. The parents reported that emotional support and information from family, friends, and health care professionals, and satisfaction with their children's level of health were primary factors in helping them to successfully incorporate asthma management into their daily lives. The finding that health care professionals were important to their adjustment is consistent with what parents reported in the study by Jerrett and Costello. As in other qualitative studies (Horner, 1997; Jerrett \& Costello; MacDonald, 1996), the parents in the Clark and Chalmers' study identified learning about asthma as essential to moving from feeling out of control or having inadequate control of the asthma situation to feeling in control of the asthma.

Englund et al. (2001) used a phenomenological approach to explore with Swedish mothers and fathers what it means to be the parents of a child with asthma. The findings from that study show similarities to the findings of quantitative studies in which parents reported experiencing stress, worry, and caregiving demands (e.g., Brown et al., 1996; 
Eiser et al., 1991; Kieckhefer \& Ratcliffe, 2000; Mailick et al., 1994; Peri et al., 1991; Staudenmayer, 1981). Englund et al. revealed that being the parent of a child with asthma was a difficult and demanding situation that required vigilance and constant care for the child, and involved an ongoing struggle to maintain control of the disease. The overall theme was "Being the parent of a child with asthma is to live a strenuous life". The parents described actions and feelings which reflected this strenuous life. The mothers acted in a protecting manner towards the child with asthma and expressed feelings of sadness about their situation. They felt that they shouldered the responsibility for the care of the child with asthma. They were constantly watching for asthma episodes to occur and were afraid of leaving the child with anyone else. The mothers worried about whether the child's asthma would improve or if the asthma would have a negative impact on the child's life. In contrast, the fathers acted in a liberating manner and expressed feelings of acceptance. They tried to liberate the child from the disease by encouraging the child to maintain his or her physical strength, and by believing in the child's own ability to handle the situation. They accepted the situation more readily and believed that the child could live a normal life with asthma. The researchers proposed that the diversity between the mothers' and fathers' actions and feelings could be viewed as complementary. However, they added that such diversity could be a difficult balancing act for the parents and may become a source of conflict between the mothers and the fathers.

\section{Summary of Literature Review}

The literature reviewed for the current study indicated that parents of children with asthma experienced stress in their lives because of their children's asthma. They 
worried about the asthma and were concerned about their children's well-being. Specifically, they had concerns about their children's future health, the long-term effects of the medications their children were taking for their asthma, and their children's overall social and emotional development, including the development of a healthy self-esteem. They also were concerned about their own ability to manage the asthma and treat exacerbations. As well, they were challenged on an ongoing basis to meet the caregiving demands related to their children's chronic condition. Asthma management placed excessive demands on parental time and energy, and caused personal strain. The parents spent a considerable amount of time and effort in attending to the demands of the treatment regime, coordinating asthma management with others, and providing support to their children, especially during symptomatic periods. The demands of caring for a child with asthma caused disruption to their daily lives and had a negative impact on their physical and social functioning. Caring for a child with asthma also caused financial strain in relation to the costs of treatment protocols.

While it was clear that parents experienced stress in relation to their children's asthma, the qualitative studies revealed that there was a process that parents went through whereby, over time, they incorporated asthma management into daily living. Although variously termed and described, the process seemed to be comprised of three phases: (a) a prediagnosis phase in which the parents experienced feelings of uncertainty about the cause of their children's repeated illness episodes and felt out of control of the situation; (b) a learning phase in which the parents learned about asthma and its management, and started to take control of the situation; and (c) a taking charge phase in which the parents 
felt in control of the situation and were able to integrate asthma management into family life.

A limitation of the body of research pertaining to parents of children with asthma is that, in most of the studies, the majority of participants were mothers. Fathers either were not included or were underrepresented as participants in the studies. There were only two studies identified that provided data pertaining specifically to fathers. In both of those studies, the discussion focussed more on gender differences than on the unique experience of the father. There was some evidence that both similarities and differences exist between mothers and fathers in their experiences with having a child with asthma. However, it is apparent from the literature review that the experiences and perspectives of fathers who have children with asthma have not been explored to any meaningful degree. Specific to this study, it is readily evident that there is a gap in the literature in relation to the lived experience of fathers who have children with asthma. 


\section{CHAPTER 3}

\section{METHODOLOGY}

Phenomenology, as described by van Manen (1994), was the method used in this study to understand the experience of fathers who have children with asthma. In this chapter, I describe how I used van Manen's approach in examining the experiences of fathers of children with asthma, the procedure for recruitment of participants, the study participants, ethical considerations, and credibility of findings.

\section{Phenomenology}

Phenomenology is a science that is concerned with the study of particular phenomena as lived experiences. As a research methodology, its purpose is to uncover and describe the meaning of a lived experience for an individual. The phenomenological researcher assumes that there is an essence or meaning to each human experience, and that this essence can be understood and described (van Manen, 1994). Phenomenology is a method of direct inquiry that attempts to investigate the totality of an experience. The researcher probes into the essence of a selected phenomenon, seeking to question and understand what a particular experience is like for a person from the perspective of the person experiencing it. This method of qualitative research is particularly useful for studying phenomena or experiences about which little is known. Because this approach focusses on individuals' experiences, it can provide rich and detailed descriptions of previously unexplored phenomena (Speziale \& Carpenter, 2003). Since the experience of fathers who have children with asthma had not been explored previously, phenomenology was the method chosen for this study. 
van Manen's (1994) approach to phenomenology is grounded in Dutch and German philosophic traditions, and is influenced by modern twentieth century movements in human science. He introduced a guide for pursuing human science research that employs traditional aspects of both phenomenological and hermeneutic methodologies. His approach is phenomenological in that it attends to "pure descriptions of lived experience" and hermeneutic in that it attends to "interpretation of experience via some 'text' or via some symbolic form" (van Manen, p. 25). van Manen proposed that hermeneutic phenomenological research consists of an interplay among six research activities: turning to a phenomenon of interest to the researcher, investigating the phenomenon as it is lived, reflecting on the essential themes of the phenomenon, describing the phenomenon through the art of writing and rewriting, maintaining a strong and orientated relation to the phenomenon, and balancing the research context by considering parts and whole. In the remainder of this section, I describe how I used those six research activities to understand the experience of fathers who have children with asthma.

According to van Manen (1994), phenomenological research starts with the researcher choosing a phenomenon of interest. He described this initial step as "turning to the nature of lived experience" (p. 31). van Manen stated that the researcher must have a deep commitment to investigating the chosen phenomenon so that the lived experience can be fully explored and understood. In this study, I turned to the phenomenon of being the father of a child with asthma. I have a long-standing interest in childhood asthma that began when my daughter, who is now a young adult, was diagnosed with asthma at two years of age. I pursued my interest in childhood asthma in my clinical practice as a 
pediatric nurse and in my academic activities as a nurse educator. I especially became interested in how childhood asthma affects parents. I was aware that limited research had been conducted regarding the paternal experience with all types of childhood chronic illnesses. However, in my clinical practice, I observed that many fathers accompanied their children to the asthma clinic. Also, fathers frequently were present in the acute care setting when their children were admitted to hospital with an exacerbation of their asthma. It was obvious that many fathers were active participants in their children's care even though their personal perspectives were not being explored. I wanted to know more about the paternal experience with respect to childhood asthma. How is a father's life affected when his child is diagnosed with asthma? How do fathers adjust to the realities of life with a child who has asthma, a chronic illness that often has an unpredictable trajectory? What do the fathers have to do in order to learn how to care for their children's asthma? Are there certain things about being the father of a child with asthma that are difficult? In this study, my aim was to explore what it is like to be the father of a child with asthma.

According to van Manen (1994), a problem for phenomenologists is that previous knowledge about or experience with the phenomenon under investigation can predispose them to interpret the nature of the phenomenon before it is fully explored. Historically, investigators were encouraged to make every attempt to avoid this problem by putting aside or bracketing their pre-existing knowledge or personal beliefs about the phenomenon (van Manen). Even though bracketing has been considered one of the central concepts of the phenomenological method of inquiry, van Manen questions whether this can truly be accomplished. He proposes that, instead of setting aside what 
we know, we should attempt to become fully aware of all knowledge and beliefs that we have concerning the experience under investigation. He says that if we attempt to set aside or forget everything we already know about a particular experience, we risk having our prior knowledge and beliefs inadvertently permeate into our reflections about the experience. For this particular study, I reflected on my own personal and professional experiences with respect to being the parent of a child with asthma. Although I did not memo or journal my own personal feelings and thoughts, I was aware of my presuppositions or personal biases, and made a conscious effort to keep them at bay throughout the entire investigation.

The second research activity van Manen (1994) described is "investigating the experience as we live it rather than as we conceptualize it" (p. 30). At this stage, the researcher actively explores the phenomenon by searching for lived experiences that may offer a deeper understanding of the nature of the phenomenon. van Manen cautioned researchers not to take anything for granted about the phenomenon. Instead, he urged researchers to approach the investigation believing that the meaning of the lived experience "needs to be found" and that "if presuppositions are suspended", all that will remain will be the lived experience (p. 53).

van Manen (1994) described various approaches to collecting human science research data; for example, observing, interviewing, and obtaining written descriptions of lived experiences. In this study, I collected data through unstructured interviews with fathers of children with asthma. The aim of the unstructured interview was to elucidate the participant's perceptions of the experience without imposing my perceptions. van Manen advised researchers to establish a strong orientation to the purpose of the 
interview before they embark upon the interview process; otherwise, they could end up with an interview that wanders off in too many different directions. In that event, the interview may lead to the generation of data that lacks sufficient substance. In an effort to avoid such a pitfall, my thesis supervisor and I developed an interview guide that I could refer to if necessary (see Appendix A). Also, because I was a novice researcher, I felt that an interview guide would help me to ensure the interviews were as complete as possible. Following each of the four initial interviews, my thesis committee members reviewed the interview transcripts and gave me feedback on my interview approach in terms of both technique and substance. Their feedback helped me to hone my interviewing skills so that I could proceed in conducting the remaining interviews.

To investigate the phenomenon as it is lived, in this study I conducted interviews with eight fathers who have children with asthma. Six of the participants were interviewed in their homes, one in his office, and one in a private room at my place of work. All interviews were recorded on audiotape. Each participant was asked to describe, as fully as possible, his experience with being the father of a child with asthma. I started each interview by asking the participant to talk about what it was like for him to have a child with asthma or by asking him to talk about the first thing that came to mind about having a child with asthma. At times, I used my interview guide in order to gain more detail about specific aspects of a participant's experience or to elicit information about aspects of the experience not spontaneously raised by the participant. When verbal cues, nonverbal cues, or both indicated that participants had completed their descriptions, I brought the interviews to an end. The interviews lasted between 50 and 100 minutes each. 
van Manen (1994) described the third research activity as "reflecting on the essential themes which characterize the phenomenon" (p. 30). He believes that as individuals reflect on experiences they have lived through, consciousness is revealed, and the themes or fundamental "structures of experience" (p. 79) can be uncovered and described. van Manen emphasized that researchers must differentiate between the essential themes of a particular experience and the incidental themes which are not unique to the experience under investigation. He stated that as researchers attempt to grasp the essential themes, they should ask themselves if the meaning of the experience would be the same if a particular theme was removed or changed.

In phenomenological research, data collection and analysis often occur simultaneously. Thus, at this stage of the research process, I began to reflect on the data generated from the interviews that I conducted with the eight fathers who had agreed to be participants in the study. My aim was to establish what it is that gives this particular experience its special significance or what makes the experience what it is. Following the completion of each audiotaped interview, I listened to the tape to start the process of analyzing the data. Each audiotaped interview was transcribed verbatim. I read each transcript several times while listening to the corresponding audiotape. This ensured that the tapes had been transcribed accurately and allowed me to gain a better overall grasp of each participant's experience. As well, it enabled me to reflect on potential themes that were emerging from the data and to identify additional questions that could be raised in subsequent interviews. Throughout the process of data analysis, I made a conscious effort to remain cognizant of my personal beliefs and knowledge, and tried to separate such 
from my interpretation of the data. By making my knowledge and beliefs explicit, I felt that I was able to reflect on the data in a more critical manner.

With each interview transcript, I used van Manen's (1994) selective or highlighting approach to identify themes that I felt were essential to the experience of being the father of a child with asthma. Each transcript was read and reread to select phrases or statements that seemed particularly essential or revealing about each participant's experience. These phrases or statements were highlighted on the text of each transcript and examined to capture the meaning conveyed. After all the interview transcripts were analyzed, I compared and contrasted the themes identified from each interview, to allow commonalties and differences to become apparent. Finally, I identified themes which best described the participants' experience of being the father of a child with asthma.

Throughout the data collection and analysis process, I held ongoing discussions with my thesis supervisor. These discussions helped me to generate deeper insights into and understanding of the data. Identified themes were discussed and refined. When all of the interview transcripts had been analyzed and preliminary themes identified, I met with my thesis supervisor and thesis committee member, both of whom are faculty members at Memorial University of Newfoundland School of Nursing, to review and validate the themes that had been identified.

Following the meeting with my supervisory committee, I arranged a second interview with seven of the eight participants. One participant could no longer be reached. Prior to the second interview, each participant was sent an interpretive summary of his interview and a list of proposed themes that had been identified from the data. The 
participants were asked to review these drafts to ensure that I had captured their lived experience in an accurate manner. The second interviews, which took place in the same locations for each participant as the first interviews, were audiotaped and transcribed in the same manner as the first interviews. The interviews lasted between 15 and 30 minutes. Once again, the selective reading approach was used to identify essential statements and phrases. No new themes were identified at that time. However, the second interviews allowed me to clarify information obtained from the initial interviews, and to confirm with the participants that the interpretive summaries and proposed themes were reflective of their experience of being the father of a child with asthma.

The fourth research activity that van Manen (1994) outlined is "describing the phenomenon through the art of writing and rewriting" (p. 30). He believes that phenomenological writing involves the application of language and thoughtfulness to a phenomenon so that what shows is precisely the phenomenon itself. In this study, I began the process of writing once the essential themes had been validated. I used quotations from the interview transcripts to exemplify the participants' thoughts and feelings, and to strengthen my interpretation of the data. Through the process of writing and rewriting, and with guidance and input from my thesis supervisory committee, I developed a clearer understanding of the emergent themes. I refined the thematic descriptions and submitted successive drafts to my committee until it was felt that I had expressed, in words, an accurate interpretation of what had been conveyed by the participants.

Maintaining orientation to the phenomenon is the fifth research activity that van Manen (1994) described. He cautions that phenomenological research can be extremely demanding of the researcher. The researcher must maintain a strong and oriented relation 
to the phenomenon of interest, aim for the strongest possible interpretation of the phenomenon, and produce a text that is rich and full of meaning. Throughout this study, with assistance and guidance from my thesis supervisor, I strove to remain strongly focussed on and committed to exploring the lived experience of being the father of a child with asthma. Through writing and rewriting of the text, I was able to explicate what it means to be the father of a child with asthma.

The sixth and final research activity that van Manen (1994) described is "balancing the research context by considering parts and whole" (p. 31). He urged human science researchers to have a clear research plan in mind, but to maintain a certain openness in the research process that will allow for unforeseeable changes that may occur. In this particular study, I had a clear research plan that was described in my research proposal and I did not need to deviate from that plan. van Manen points out that researchers should give thought to "organizing one's writing" (p. 168) so as to best reflect the nature of the phenomenon being explored. He offers some suggestions for textually organizing phenomenological writing, but emphasizes that researchers can use a combination of approaches or even "invent" an approach (p. 173). I used the thematic approach for writing my analysis of the data from this research study. In that approach, the thematic analysis is divided into sections in accordance with the identified themes. Each heading states the theme that is being described in that section. The five themes together reflect the whole of the lived experience of being the father of a child with asthma. 


\section{Procedure for Recruitment of Participants}

Permission was obtained from a local health care corporation to recruit participants through an outpatient asthma program (see Appendix B). The nurse coordinator of the program agreed to act as an intermediary in contacting potential participants who met the inclusion criteria. She approached fathers in consecutive order as they visited the clinic with their children. All fathers who were approached agreed to participate in the study. Participants were recruited until the descriptions of their experiences revealed redundancy and no new themes were identified from data analysis. Eight participants were sufficient to capture the lived experience of fathers of children with asthma.

\section{Participants}

The eight participants in this study were fathers of children with asthma. They were recruited from an outpatient asthma program at a local pediatric hospital. The study participants met the following inclusion criteria. They (a) had a child under 13 years of age who had been diagnosed with asthma, (b) were able to give informed consent and understand the interview procedure, (c) lived within a 20 mile radius of St. John's to allow for accessibility for interviews, (d) were 19 years of age or over, and (e) were able to understand and speak English. The restriction of the study group to fathers whose children were under the age of 13 years is related to the fact that parental involvement in asthma management with teenagers may be considerably different than that with younger children. Teenagers often manage, or play a major role in managing, their asthma. Also, developmental transitions during adolescence and subsequent adjustments in parenting 
may affect the experience of fathers of adolescent children compared with that of fathers of younger children with asthma.

Personal information collected from the participants (see Appendix C) revealed that they ranged in age from 39 to 46 years. All of the participants were married and living with their wives. Four of them held university degrees and four had completed at least six months of post-secondary education. Three of the participants were employed in the professional sector, three were employed in the nonprofessional service sector, and two were unemployed. One father had three children with asthma. The remaining seven fathers each had one child with asthma. With regard to the children with asthma, there were four girls and six boys ranging in age from 7 to 11 years. They had been diagnosed with asthma for a period of 2 to 6 years. Two of the children had moderate asthma and eight had mild asthma, according to information given to each father by his child's physician.

\section{Ethical Considerations}

Permission to conduct the study was obtained from the Human Investigation Committee, Memorial University of Newfoundland (see Appendix D). Initial contact with all potential participants was made by an intermediary who was familiar to them and who was not involved in conducting the research. After informing them of the study and ascertaining their interest in participating, the intermediary obtained their permission to release their names and telephone numbers to me. During the initial telephone contact with each father who had expressed interest in participating in the study, I outlined the purpose of the study, the nature of their participation, and preservation of confidentiality. 
I stressed the voluntary nature of participation, including freedom to withdraw from the study at any time.

Prior to commencing the initial interview, each participant signed a written consent (see Appendix E). The consent was reviewed with the participant, and an opportunity was provided for each person to voice concerns and seek clarification of any issues. Each participant was provided with a copy of the consent form that included my name and telephone number. They were advised that they could contact me at any time during the study if they had questions or concerns. I again stressed the voluntary nature of participation and, once again, participants were informed that they could withdraw from the study at any time. Participants were informed that they might not personally benefit from the study, but that the study may result in new knowledge concerning the experience of being the father of a child with asthma. Participants were told that there were no anticipated risks from participating in the study. However, I stressed that if any sensitive issues were raised during the conduct of the interview, they could stop the interview or refuse to respond to any questions that they would prefer not to answer. I made every effort to be sensitive to the participants' verbal and nonverbal communication. Throughout the interviews, none of the participants demonstrated any discomfort in discussing any aspect of their experience.

I took all reasonable precautions to protect the identity of the participants and to ensure confidentiality of all data. The interviews were conducted in private, at a time and place that was convenient for the participant. The participants were identified only by a code number on all audiotapes and transcribed data. The consent forms, audiotapes, transcripts, code numbers and demographic sheets were kept in a locked drawer in my 
home. The typists who transcribed the interviews were instructed about the importance of maintaining confidentiality and took an oath of confidentiality prior to beginning the transcriptions. Audiotapes will be erased and all written materials will be shredded once the study is completed and findings are published.

Participants were advised that the completed study would be available at the Health Sciences Library, St. John's, and that portions of the study may be published. They were told that direct quotations from their interviews would be used to support identified themes but that their anonymity would be preserved.

\section{Credibility of Findings}

Credibility refers to the trustworthiness of the findings in a qualitative research study. A qualitative study is credible when participants recognize the reported research findings as their own experience (Speziale \& Carpenter, 2003). The participants in this study were asked to review a summary of the transcribed copy of their initial interview and a list of probable themes that were identified following the preliminary analysis of the data. During the second interviews, participants confirmed that the summaries and the proposed themes were reflective of their experience.

Another method of increasing credibility is through peer examination which involves the researcher discussing the research process and findings with people who have experience with qualitative methods (Beck, 1993; Krefting, 1991). In this study, my thesis supervisory committee was composed of two faculty members from the School of Nursing, Memorial University of Newfoundland. One committee member has clinical expertise in the area of asthma and the other member has expertise in the 
phenomenological method. They read the transcripts, discussed the thematic analysis with me, critiqued my findings, and contributed to deeper analysis of the data. 


\section{CHAPTER 4}

\section{FINDINGS}

Themes identified from the analysis of the interview transcripts of the eight fathers of children with asthma were: feeling relief in knowing the diagnosis, learning the ropes, living with concern, being vigilant, and being comfortable with asthma management. This chapter provides a discussion of each identified theme, supported by selected quotes from the interview data.

\section{Feeling Relief in Knowing the Diagnosis}

For the fathers in this study, the diagnosis of asthma in their children was met with a sense of relief. The diagnosis provided relief in that it gave a definitive cause for the repeated illness episodes the children had been experiencing, led to a specific treatment plan, and ruled out the presence of a disease with a poor prognosis.

All of the fathers described a period of time, prior to receiving the diagnosis of asthma, during which their children experienced recurrent episodes of respiratory illnesses. The children were distressed and uncomfortable with persistent symptoms such as chronic coughing (especially at nighttime), nasal stuffiness, wheezing, and shortness of breath. Sometimes the children became ill for prolonged periods, especially when they had the common cold.

When she [daughter] would get a cold she would get very sick with it and it took her a long time to recover from it.... we were taking her back and forth to the doctor. We weren't really aware that she was short of breath and I guess maybe because she was so young, she didn't realize what the problem was herself.

Some fathers reported that their children's illnesses seemed to encompass a variety of symptoms that had no recognizable pattern. They were unable to make 
sense of what was going on. One father commented thus:

Well, I didn't know what was wrong at first... I thought she [daughter] had the flu or something...she wasn't eating and she was getting sick and tired all the time.... She had no energy.... In the nighttime when I used to check on her...she was just going [mimics noisy breathing] like she was trying to get her lungs filled up with air.

The fathers related how they attempted to alleviate their children's symptoms with over-the-counter medications and comfort measures. However, the children's illness usually did not resolve with those interventions. They ended up making repeated trips with the child to their family doctor or the emergency department of the local hospital.

We went through a period of time when [son] was constantly getting sick and would go through these periods of very severe bouts of coughing.... We thought it was just part of a bad cold. But it would get to the point where... he was always in such distress that something had to be done and we would go to the hospital.

The prescribed treatments provided temporary alleviation of symptoms but offered no long-term resolution to the illness episodes their children were experiencing. The children seemed to be constantly sick and in need of medical care.

It took varying periods of time, ranging from six months to three years, before the diagnosis of asthma was confirmed. The fathers reported that they felt a sense of "relief" to have a diagnosis established. Now that the cause of their children's repeated illnesses had been found, they no longer had to speculate about what was wrong with them. They were relieved to know the cause for their children's symptoms. As one father stated, "It was a relief, really, because then we knew what he [son] had." All along, the fathers had been concerned about their children's frequent illnesses. The diagnosis of asthma seemed to legitimize, as well as offer relief to, their concerns. The following commentary captures one father's feelings in that regard. 
Ifelt relieved when a diagnosis was actually discovered because we had gone through so many years.... of disturbed sleep, chronic coughing and sniffling, and that [the diagnosis] made everything clear. It meant, okay, she is not just a child that has a lot of colds, and she is not just a child who coughs a lot for no reason.... it made it clear to us as to the reasons why she was having the problems she was having.

Prior to the diagnosis, the fathers had been handling their children's illnesses in a fragmented and reactive manner by treating the symptoms as they occurred. Along with the diagnosis, came a specific treatment plan. This contributed to the fathers' relief because they felt they would be able to take action not only to alleviate their children's symptoms, but also to improve their overall health, comfort level, and quality of life.

There was a relief in just knowing that we would be able to treat it and see some improvement and, therefore, make her [daughter] more comfortable.

Now that the fathers knew what they were dealing with, they saw a means for long-term management of their children's ongoing illness episodes.

There was a sense of relief that at least now that we know what this is... there would be some possibility of managing it...there is a diagnosis and a treatment that goes along with this.

The fathers also were relieved to learn that their children's symptoms were caused by asthma and not by some other disease of a more serious nature. They did not perceive asthma to be a significantly severe disease and certainly did not see it as life threatening. Instead, they viewed asthma as a manageable disease with a good prognosis. They did not want their children to have any type of chronic illness but, since that was not to be the case, they were relieved that the chronic illness they had to deal with was asthma. A common feeling among the fathers was that "things could be worse", given some of the other chronic illnesses that families and children have to face. As one father stated,

With all the possible afflictions that one could have that might be life lasting, this didn't seem to be a terribly onerous one. 


\section{Learning The Ropes}

After receiving the diagnosis of asthma, the fathers went about what could best be described as 'learning the ropes' of asthma management. Learning the ropes entailed gaining the knowledge and skills that were required to manage their children's asthma in an effective manner. The fathers had to learn about asthma, the medications and how to manage the medication regime, and about asthma triggers and environmental control strategies specific to their particular child's asthma. In addition, they learned the ropes through experiential learning that came as a result of being involved in the day-to-day care of their children.

At the time their children were diagnosed, most of the fathers in this study knew very little about asthma other than that it was a breathing disorder and that it was treated with inhaled medications. There were a few fathers who had a greater knowledge of asthma, but they too were aware that they needed to learn more about asthma, especially childhood asthma. As one father said,

I had a basic understanding... of the asthma process.... But you also need ...information in regards to medication and other things which I did not have with my basic background.

The fathers felt that it was essential to be knowledgeable about asthma in order to be able to recognize and treat their children's symptoms, and attain an adequate comfort level for their children. They wanted to know about the treatment and what they could do to help their children. Their response upon being told that their children had asthma was exemplified by this father who stated that immediately he wanted to know about the treatment. 
My response to it was, 'Now we have to get a protocol together so we can treat this and get this managed properly... Okay. Now, what's the next step?'.

Initially, the fathers learned about asthma from the health care professionals who were involved in their children's care. They were provided with information about asthma, medications, and the environmental controls that were necessary to minimize the child's exposure to asthma triggers. They also were shown how to use the prescribed medications. For some fathers, the education was provided through a formal teaching session with the asthma educator at the local pediatric hospital. Other fathers said the child's pediatrician was their main source of information. The fathers were highly receptive to and satisfied with the education that they received. As one father commented,

A lot was going through my mind.... and it was nice to see that somebody was there to show us what to do because I really didn't know.... She [asthma educator] showed us how to use the puffers and told us about them.... She gave us a lot of pamphlets.... She was a great help.

After the initial contact with health care providers, a few of the fathers continued to learn about asthma through their wives, rather than through further direct contact with health care providers. They explained that their reliance on their wives in that area was due mainly to practical reasons and not due to lack of involvement in their child's care. For example, one of the wives was a health care professional who had some degree of familiarity with asthma. That father explained how he relied on his wife for informational support as follows:

....because my wife is a [health care professional]....I relied on her for information.... Normally, I am a very inquisitive type of person and...like to get all the details... but she [wife] took the lead there.... I relied on her in that area more so than I would in other areas. 
The information that the wives passed on to their husbands was in the form of verbal explanations and printed materials obtained from the child's pediatrician. The fathers read the literature they were given, discussed it with their spouse and, as one father said, "We took it from there."

The fathers felt there was a lot to learn. One father stated, "There was a big learning curve and it didn't just happen overnight." Although the fathers felt satisfied with the information they received from their health care providers and, for some, that provided by their wives, they still went on to gather further information about asthma from other sources. Thus, they increased their knowledge of asthma in an ongoing manner. One father described how he looked to colleagues and friends for factual information about asthma.

... information came from... colleagues and friends that I have who are in healthcare, and just getting a lot of pamphlets and written materials as well as getting a lot of advice from these people. I was able to pick their brains.

Another father explained how he increased his knowledge and gained practical information by talking to people who themselves had experience with asthma.

I've learned from talking to other people who have asthma and who have children with asthma.... Things that have caused triggers for them you are now aware of and you watch for in your own child. Things that are beneficial for their children you may also try with your child.

The fathers became "tuned in" to asthma. As a result, they zoned in on any information on asthma that they came upon in their normal day-to-day living, such as newspaper and magazine articles or television and radio programs. As one father stated, "If I saw ...an article about asthma...I read it. I wouldn't have before [child was diagnosed with asthma]". Another father, who described asthma education as "an ongoing thing", spent 
a considerable amount of time searching the Internet for information about asthma in an effort to learn as much as possible about trends in asthma treatment.

As part of learning the ropes, the fathers had to learn how to manage the child's medication regime. Prior to the diagnosis, the children had been given medications only when they were symptomatic. When the children were diagnosed with asthma, they were started on medications that had to be administered at regular periods throughout the day, even when the child was not symptomatic. Consistency with the medication regime required more effort than the fathers thought it would and they had to learn to make it a part of their family's everyday routine. One father said,

We had to be more regimented because... the medications that were prescribed for [daughter] were not part of our daily routine.... It took some getting used to.

Over time, the fathers learned about their children's asthma triggers and environmental strategies to control the triggers. They became aware of the necessity of modifying the home environment in an effort to reduce the child's exposure to allergens or irritants that could trigger an asthma episode. They implemented measures to reduce or eliminate irritants such as cigarette smoke and scented products (e.g., household sprays and cleaners), and known allergens such as dust. A "no smoking" rule was implemented in the home. The fathers who were smokers gave up smoking because of their children's asthma. Some of the fathers made costly changes in their homes such as replacing carpets with hardwood flooring, and installing devices to control humidity and reduce dust particles. Other fathers were more restricted in what they could do, for example, fathers who were living in rented homes or who had financial constraints. However, these fathers still tried their best to protect their children from triggers in the home. One father 
explained how he negotiated an agreement with his landlady whereby he would do renovations to their rented house free of charge if he could make modifications that would improve the home environment for his child.

I renovated the house. I took up all the old, dusty carpet and put down indoor-outdoor carpet that was easier to keep clean. We put in new windows and doors to get rid of the mould and mildew.... It was that or move to some place else.

Another father, who couldn't afford the expense of replacing the flooring in his home, initiated the environmental controls that were feasible and monitored his child's asthma carefully.

We spray [Allergex] all around his room.... and around the house....the living room, carpet and chesterfield.... We got pillow covers.... and now he's got a waterbed instead of a regular bed....

Through their learning, the fathers had recognized the importance of environmental control to the management of their children's asthma. They would have done whatever was necessary and within their means to improve the home environment for their children. As one father stated,

We got his [son's] asthma under control so we didn't have to go through the expense of replacing carpets.... But if it came right down to it and we had to do that, well, we would've done that [replaced the carpets].

Much of the fathers' learning occurred as a result of being involved in their own child's care. By being actively involved in the day-to-day asthma management, they became familiar with specific characteristics of their particular child's asthma. They came to know the child's presenting symptoms. As one father said: "There is a distinct asthma cough that you get used to. "Fathers also learned to pick up on other less obvious symptoms of an impending asthma episode, for example, 
[Son] often gets dark shadows under his eyes. That is a sure sign. And he may start breathing a little faster when he is asleep.

Another father, who felt he had become very "tuned in" to his child's asthma symptoms, said, "We can almost forecast what will happen." The fathers came to learn how their children responded to the different medications and how the medications worked to alleviate their children's symptoms. As they became more familiar with their children's asthma, they learned, in collaboration with their physician, how to adjust their children's medications in situations that could cause a flare-up of the child's asthma or at times when early symptoms of an impending flare-up were present. Thus, they learned how to take a proactive approach to asthma treatment. As one father described,

We learned that exercise...induces it ....Now when she's playing soccer, for example,... she will take her puffer five or ten minutes before she starts playing... and she'll be all right.

Not only did the fathers learn to anticipate the need for medications, but they also learned how to wean their children off the stepped-up treatment. They wanted to be able to use the medications in a judicious manner, thus maintaining good management of the medication regime. At the same time, they wanted to do the best they could to help their children return to a state of wellness and in a timely manner. As one father stated,

When [son] is ill, we try to control his medications to make sure that it's a pretty smooth transition from illness to wellness.

\section{Living With Concern}

It was apparent from the fathers' descriptions of their experience that they had a number of concerns that made them feel uneasy about some aspects of their children's asthma. The concerns were focussed around their children's prescribed medications, safekeeping at school, and overall well-being. Although these concerns were not at the 
forefront of their thoughts every day, they were a part of their experience in being the father of a child with asthma. These concerns would arise most often when the children were acutely ill. One father stated,

Your concerns are magnified when the children are not well; they are reduced when they get better. I think we have the tendency to feel very comfortable as to what we are doing when the children are responding and you become really aware of...them [concerns] when the children become ill.

The fathers' most prominent concern was with respect to their children being on medications during childhood. They wondered about the long-term effects of the medications, especially since the children had started taking them at such a young age. The fathers knew that their children would need to take these medications for an indefinite period of time, perhaps for the rest of their lives, thus increasing their risk of incurring harm or injury from the drugs. As one father stated,

The side effects of the drugs, that would be used to treat someone longterm, was my biggest fear, not the asthma itself.

The fathers particularly were troubled about the potential adverse effects of both oral and inhaled corticosteroids. According to one father, "Steroid seems to be a bad word. " All of the children were receiving inhaled corticosteroids, either on a regular or intermittent basis. As well, they had received oral steroids on at least one occasion for the treatment of an acute asthma episode. The fathers were apprehensive about how the steroids might affect their children's growth and development.

I didn't want to see him on any type of steroid product, especially at his age.... to put a child on steroids, even a small dose, I was fearful that it would inhibit his long-term growth.

For some fathers, their concern about the use of inhaled corticosteroids was compounded by the fact that, to the best of their knowledge, current research about these medications 
pertained to relatively short-term use of the products. They felt that there was a degree of uncertainty in the medical community about the effects of long-term use.

...I know they test them [inhaled corticosteroids] for considerable periods of time but the effect that something may have over a two-year period or three-year period may be different than if it is over a fifteen or twenty-year period. And, I guess nobody knows the answers to these questions.

Even though the fathers were troubled about their children's medications, they acknowledged that their children's asthma symptoms had improved significantly after they started using them. Therefore, they were faced with the dilemma of complying with a treatment that, on the one hand, was beneficial to their children but, on the other hand, could have a negative impact on their children's long-term health. The fathers contemplated the benefits of using the medications against the risk of their children incurring long-term adverse effects from these same medications and tried to reconcile their concern. As one father stated,

You read some studies that state uncontrolled asthma can lead to irreversibly damaged lungs that will not mature fully and that don't have their full capacity. So the untreated state seems worse than the side effects of the actual treated state.

The fathers wanted their children to get relief from the asthma symptoms; hence, they ensured that their children received their prescribed medications. But, in complying with the medication regime, they had chosen the lesser of two undesirable options. One father said,

I'd rather see him [son] take the medication than to be suffering with the asthma.

In addition to concern about medications, the fathers expressed concern about their children's safekeeping at school. Much of that concern centered on policies pertaining to the use of medications in the school setting. Although there was some 
variation in the policy among schools, none of the schools permitted students to carry medications on their person. Medications were required either to be locked up in the main office or kept with the homeroom teacher. For the most part, the fathers understood the need for the schools to have control over medications but they felt that policies required some flexibility regarding inhaled medications for children with asthma. The fathers were frustrated because they knew that if the child became symptomatic, he or she would need to use a bronchodilator right away. One father described his frustration as follows:

Unfortunately, the schools have a funny policy that you can't keep medications with you. We found that kind of bizarre because if [son] gets into a coughing fit, the last thing he needs to be doing is trotting down over two flights of stairs [to school office] to get his medication, take it, and then have to trot up two flights of stairs back to the classroom.

In some cases, the medications were kept in the school even when the children were outside during recess and lunch break. This added to the fathers' concern because, if the child became symptomatic, a further barrier was added to the child's access to the required medication.

I think he [son] should have his puffer with him because he is the one who knows if he needs it. If he gets in distress, he has got to go back into the school and find the teacher who has the puffer.

Sometimes, conflicts arose between parents and teachers concerning the medication policy. In those cases, the problem was discussed with the teachers and usually some degree of resolution followed. For instance, a father related how school policy prohibited his son from using his inhaler in the school setting unless one of the parents was present. The father intervened to ensure that his son could use his inhaler on his own while in school.

He used to have to take his puffer every four hours. For a while, they would not let [son] take the puffer in school. We told the teacher that he 
takes his puffer at home and that he is able to do it on his own and should be able to do it at school....they [school personnel] backed down after a while.

Some fathers were "living with" the school policy because, up to that point, their children had not experienced an asthma attack at school. Several fathers admitted that they "cheated" on the school policy and allowed their children to carry their puffers with them while in school, even though they knew it was against the school policy.

So we sent him to school with it [the puffer] and said, 'Just keep it in your book bag and if you got to use it, just use it and we 'll take it from there.'

Another concern regarding the school setting was with respect to the risk of the children becoming exposed to environmental irritants or allergens that could trigger an asthma attack. The fathers were aware that such activities at school as having animals in the classroom, arts and crafts, physical education, and school maintenance and renovations could be problematic for their children. As well, the fathers believed that the air quality in their children's schools was poor and that it could have a negative impact on their children's asthma.

That [air quality] is a great concern... it is an issue in our school ... We are aware ... that [poor air quality] may make [son's] situation worse.

That concern had been highlighted for them by recent reports in the media which had drawn public attention to the issue.

In addition to indoor triggers, the fathers also were concerned about potential triggers outdoors at school. Along with outdoor allergens, such as pollen and grass, there were other factors such as cold air, changes in the weather, and physical activity that could cause an asthma attack or cause a child's asthma to worsen. For instance, the child could be outside during recess period and lunch break when the weather was poor or be engaged in vigorous play activity with schoolmates. 
The fathers tried to take measures to shield their children from potential triggers in the school setting. However, quite often they ended up being frustrated with the response they received from the school. Thus, the fathers' concern about the school environment was heightened by the fact that, in many instances, they were met with opposition and lack of sensitivity on the part of the school authorities in their attempts to promote a safe environment for their children with asthma. As one father, who took measures to have his child stay inside on days when the weather was cold and damp, related,

... one day when it was cold and raining, he [son] was out at lunchtime.

That upset me.... because that [the weather] causes his asthma to act up. So I phoned the school. The principal told me: 'Well, there's lots of children with asthma in the school and it doesn't seem to bother them'.

The fathers had to be persistent in their efforts to effect change, as exemplified by this account.

We thought of some trigger in the school because we were doing everything that we should at home but he was still having the [asthma] attacks. There was an old, dusty carpet in his classroom. I wanted it removed. The principal was not going to cooperate first but ... he came around. I think we have that under control now.

Along with the specific concerns regarding medications and school, the fathers talked about three other, more generic concerns about their children's well-being:

First, they were concerned with the ongoing discomfort that their children experienced with the asthma and were especially troubled when the children were symptomatic. One father said,

The chronic discomfort that the children go through, especially when they have exacerbations of their asthma, is a big concern for me. You know that they are not really at rest, whether it be sleeping or at play or just socializing with their siblings. There's like a constant irritation that they have and they are just not comfortable. 
Second, they worried that the asthma might become more severe in the future. That concern was particularly prominent early in the diagnosis because the fathers really did not know what to expect. Although, over time, some of that concern was muted by the fact that the child's asthma had stabilized, it persisted to some level as evidenced by this father's account.

...first when he [son] had asthma...I wondered, 'How bad is this going to get? Is he going to be on medication for the rest of his life?'.... Now that his asthma is under control... it doesn't bother me as much as it did...but it still concerns me.

Third, they worried about how their children would manage their asthma when they became teenagers. The fathers recognized that as children become increasingly independent of their parents, parental involvement in asthma management is different than when the children are younger. They could foresee that an increasing amount of decision-making would be handed over to teenage children. The fathers were concerned that asthma management would not be given high priority or would be neglected all together when their children became teenagers. Furthermore, there was concern that, as the children grew older, they may begin to minimize or mask their symptoms in order to carry on with their social activities.

And I can see that is going to be an increasing problem. I think that [son] is going to want to minimize it [his asthma] because it's not an adventure to go to the hospital any more because it takes him away from other things that he'd rather be doing.

The fathers dealt with that concern by endeavoring to educate their children about their asthma. Their hope was that their children would approach adolescence with a good basic knowledge of the condition, along with the skills that would enable them to self-manage their asthma effectively. 
One of my biggest concerns... is to make sure that the children are armed with as much knowledge as possible to be able to cope with their asthma effectively when they are teenagers.

\section{Being Vigilant}

The fathers were vigilant with respect to their children's asthma. They constantly looked out for their children and kept a watchful eye over them. They looked for symptoms of asthma and for situations which could bring the child into contact with asthma triggers. Vigilance became a routine part of the child's care.

Sometimes just even in the ordinary interaction that you have in touching him [son]...you sort of feel or hear or listen for a tightness in his chest. It has become a habit.

The fathers wanted to be able to intervene in a timely fashion so as to avoid a serious asthma episode. Thus, they were vigilant for symptoms that could indicate a potential flare-up of their children's asthma.

He [son] would say I can't breathe very well and then... we look for other signs of a flare-up.

Vigilance with respect to asthma symptoms extended to other children in the family who did not have asthma. Now that the fathers had knowledge of asthma, they knew what to look for and were able to recognize asthma symptoms should they occur. They felt that by being watchful for symptoms of asthma in the siblings of the affected child, they would be able to seek medical attention in a more timely and informed manner than in the past, should the need arise.

Because of the older child [who has asthma], there are things that we would pick up on more quickly than before.... There is a passive vigilance in that area.

The fathers' vigilance of their children's asthma status entailed collaborating with their spouses. Together, they monitored the asthma by using such techniques as keeping a 
diary of the child's asthma symptoms, documenting peak flow measurements, and assessing the child's overall well-being on a daily basis.

The fathers wanted their children to be vigilant of the asthma as well. They encouraged their children to report symptoms as they arose. One father pointed out, We are trying to teach [son] that he must also be vigilant... and that it is not only us [who need to be vigilant].

In addition to keeping a watchful eye for symptoms, the fathers also were alert to situations in which the children could be exposed to asthma triggers. They recognized that even routine activities around the home could bring the children into contact with potential triggers for an asthma flare-up.

You have to watch out for many things.... Even silly things like when he [son] wants to be around me...cleaning the car and stuff like that. I am fearful of atomized sprays that can trigger an attack.

The fathers' vigilance for triggers extended outside the home as well. They were mindful of the many potential triggers in the outdoors to which their children could be exposed.

You are always watching. For example, when the pollen season starts, $I$ will have to tell [son] not to go out in the backyard... and keep an eye to make sure he doesn't. That [the pollen] really causes his asthma to act up.

Asthma was always in the forefront when planning family activities and outings. The fathers had to be mindful of bringing their children into situations that could trigger an asthma attack.

You always have to think about the environment you are entering...there's a lot of forethought in planning activities. Vacations have to be well thought out.

During the school year, the fathers were on the alert for reports of widespread respiratory infection in the school setting. Since respiratory infection was a common asthma trigger, 
the fathers were vigilant for indications of it in their children so treatment could be stepped up early. As one father related,

It is important for us to try and stay on top of it so that we do not reach one of those acute phases where we have to go to the hospital.

For some of the children, exercise triggered their asthma and so the fathers were vigilant when their children were engaged in any such activity. For instance, a father whose daughter had exercise induced asthma, routinely accompanied her to sporting events to monitor her performance and ensure that the activity was not aggravating her asthma. He stated that because his daughter had asthma, he was highly cognizant of her performance in these activities.

I watch how she [daughter] is performing. If I notice a change in how she's playing, that's one of the first things that comes to mind. Is she feeling okay? Is her asthma acting up?

In being vigilant for triggers, there were times when the fathers had to be almost like detectives as they tried to determine the cause of particular asthma symptoms or acute flare-ups. For example, one father noted that his son's asthma was symptomatic each year when he returned home from summer camp. Upon reflection, he thought of several environmental factors in the summer camp that might have contributed to these flare-ups.

... at camp there was a building that had a wood stove and the beds were downstairs, probably very dusty and hardly ever cleaned. I felt there was a problem with the air quality there.... the last couple of years I didn't let [son] go because... his asthma would act up after that camp.

Similarly, there were instances when the fathers suspected that particular factors were triggering their children's asthma. In those situations, they had to be vigilant for indications of an asthma episode when these factors were present. For example, one 
father noted that his son's asthma seemed to be adversely affected by sudden changes in the weather. He pointed out:

We really have to watch the weather changes because I think that [son's] asthma may be triggered by that. It seems there may be something going on there which aggravates his asthma.

Although the fathers were constantly watchful of their children, they tried not to overprotect them. They wanted to shield their children from situations that could trigger an asthma episode, while at the same time allow them to lead as normal a life as possible. For example, a father was incurring situations with his children whereby they wanted to spend time at their friends' homes even though environmental factors were present which could aggravate their asthma. He was cognizant of his children's need to be with their peers.

You want the children to lead as normal a life as possible so you try to compromise a little bit and you medicate them when they go, when they come home, and you monitor the amount of time that they are there...You can be as vigilant as you can, but...you want them to be like their friends.

\section{Being Comfortable With Asthma Management}

Despite the fact that the fathers had a number of concerns about their children's asthma, they expressed confidence in their ability to take charge and manage it on a dayto-day basis. One father stated, "We feel quite comfortable, you know, in dealing with the situation now". That feeling was shared by all of the fathers. There were a number of factors that positively influenced the fathers' experience and enabled them to feel confident in managing their children's asthma.

The acquisition of knowledge about asthma was one of the most important factors. Understanding the disease process, the medications, and the rationale for the 
treatment plan helped them to appropriately carry out the activities involved in their children's care.

I think understanding the disease, understanding why you're doing what you're doing makes it a lot more comfortable to deal with....I think that is invaluable in your overall acceptance of it.

In addition to acquiring factual knowledge about asthma, the fathers gained valuable experiential knowledge that enabled them to develop a clearer picture of the total situation. As the fathers gained experience in treating their children's asthma, they became more confident in their ability to manage it, especially when it came to dealing with acute episodes.

After you experienced it [acute episode] a few times and saw that you knew how to deal with it, then you became more comfortable in dealing with it.

The fathers' comfort level with asthma management increased as they saw their children respond positively over the long term to the prescribed treatment plan. They came to know that the prescribed medications relieved their children's respiratory symptoms and helped the children to feel better. That was comforting for the fathers because they could see their children's breathing patterns and overall health status improve. They no longer had to see their children feeling acutely ill for prolonged periods. The children themselves reported that they felt better and the fathers derived satisfaction from knowing that their efforts were having a positive result.

After she [daughter] was diagnosed and after she was on medications for a while, she said one night 'You know, Daddy, it's like I can breathe again'. So that is what she said - she could breathe again and things became a lot easier for her. That made it a lot easier for me.

The fathers had supportive spousal relationships. Ongoing discussion and collaboration with their spouses about the asthma gave the fathers a sense of togetherness 
and a feeling that they were working as a team in the day-to-day management of their children's asthma. As one father stated, "We are in this together. We lean on each other." Another father expressed how he felt "fortunate" to have a supportive spouse whom he could "bounce things off and find support in". Similarly, a father, who said that he tended to be "something of a worrier", described how his wife helped to alleviate his worry when their son was ill by talking to him and reassuring him that the situation was under control.

I tend to worry....about things.....my wife is calmer....and so she says 'Don't go worrying about that [son's asthma]'.

There was a sense that each couple had mutual support and collaborated well together.

It [daughter's asthma] has brought my wife and I closer together...Just watching [daughter] ... and talking about it [daughter's asthma]. We're closer because of it.

In addition to supportive spouses, the fathers had encountered supportive and understanding health care professionals. The availability of professional help and the knowledge that they could easily access health care professionals if they needed them was reassuring for the fathers.

It takes the worry off me.... The hospital is just down the road.... [Pediatrician] even gave me his home phone number so if we had any questions anytime whatsoever to give him a call.

The fathers had confidence in the health care providers and were pleased with their children's care.

... the doctor and the nurses at the clinic. We always felt very comfortable with how they were handling the situation and with the information they provided. So that gives you more confidence in dealing with it. The way the staff dealt with it... they seemed to put you at ease. 
Along with their spouses and the health care professionals, the fathers also drew on support from friends and family members who had personal experience with asthma. The fathers regarded these people as role models for good asthma management. For example, a father who had a nephew with asthma commented:

I...used my sister as an example.... She was doing a good job [in managing her son's asthma]...I just saw how she was taking care of her situation...I felt if she could do it, so could I. I didn't think it was a big job for her.

Similarly, another father whose wife had asthma as a child, described how he felt strengthened by the knowledge that his wife's parents had been able to handle her asthma.

...my wife's mother and father said when she [wife] was young she had some real serious attacks.... but they coped with it, so we looked at it that we got to cope with it.

The fathers acknowledged that not all families had access to this type of support from family and friends. They felt they had an advantage over many other families of children with asthma in that regard. For example, one father said he felt "almost lucky" to have a family member who was sharing a similar experience.

The fathers in this study had a positive attitude, which enabled them to be comfortable with their situation. Instead of focussing on problems, they directed their energies toward identifying and implementing effective asthma management strategies. Their attitude allowed them to see the positive aspects of their situation. For example, the fathers felt "fortunate" that their children's asthma was not severe because that meant better control and less disruption in family life than if the asthma had been of a more severe nature. As well, the fathers verbalized a sense of hope and optimism for the future. They were hopeful that their children would "grow out of the asthma" because their 
pediatrician had told them of that possibility. They were optimistic that future research would produce new and improved treatment for asthma. In addition, the fathers tended to look upon their child's asthma as "just another thing that happened" in their lives. One father said, "It's something else I have to do. It is just something else that came along." In their view, fatherhood brought with it a lot of responsibilities and now that their children had asthma, they accepted it as one such responsibility. They approached asthma management in the same way that they approached the other duties of fatherhood. As one father stated,

...it's a part of life. So you have to say fine, that's the cards that were dealt to me and we have to deal with them. 


\section{CHAPTER 5}

\section{DISCUSSION}

The findings from this study provide new insight into the experience of being the father of a child with asthma and there are particular aspects of the experience that provide support for previous research findings in the literature regarding parents and childhood asthma. This chapter provides a discussion of each theme identified in this study and relevant literature.

\section{Feeling Relief in Knowing the Diagnosis}

The fathers in this study experienced a sense of relief once a diagnosis had been made for their children's repeated episodes of respiratory illnesses. The fathers described a prediagnosis period during which they did not know what was wrong with their children. During that time, the fathers were concerned about their children who were often sick and in need of medical care. Other researchers described a similar prediagnosis period, during which parents of children with asthma were confused by, and uncertain and concerned about, their children's recurrent illness episodes (Horner, 1997; Jerrett \& Costello, 1996; MacDonald, 1996).

The fathers were relieved to know what was causing their children's illnesses and that a specific treatment plan could be implemented. These findings are consistent with previous findings in which parents reported similar feelings of relief when, after a period of uncertainty in the face of their children's repeated illness episodes, the children were diagnosed with asthma (Horner, 1997; Jerrett \& Costello, 1996; MacDonald, 1996). The fathers were relieved that the diagnosis was asthma, a condition that they perceived to be manageable and having a good prognosis, and not some condition with a less favorable 
outcome. The fathers in this study had family members or friends who had personal experience with successful asthma management and that may account for their perception of asthma as a disease that was not particularly serious or life threatening.

Feeling relief in knowing the diagnosis points to the importance of having a diagnosis early so as to provide relief to parents who are dealing with the unknown as they care for their ill children. Parents need to know what they are dealing with so they can manage it effectively. Until they know the diagnosis, it is difficult for them to know what to do. Without a diagnosis, they may be imagining a worse problem. Once an accurate diagnosis is established, parents can develop a realistic perception of the condition and its management requirements.

\section{Learning The Ropes}

After receiving the diagnosis of asthma, the fathers recognized that they needed to learn about the condition. They wanted to be able to take measures to alleviate the asthma symptoms and relieve the discomfort that their children felt when they were symptomatic. They were eager for information about asthma and its management, and made a conscientious effort to apply their learning. Parental perceived need and desire for information about asthma has been documented in a number of previous studies (Kieckhefer \& Ratcliffe, 2000; Kurnat \& Moore, 1999; Syndor-Greenberg \& Dokken, 2000; Whyte et al., 1995).

In addition to accessing information from health care professionals, the fathers in this study also sought out information about asthma from many other sources. In previous research studies, information seeking was identified as a strategy that parents used as they began to deal with asthma management (Clark \& Chalmers, 2003; Jerrett \& Costello, 
1996; MacDonald, 1996). MacDonald reported that, after the diagnosis of asthma was confirmed, the mothers in her study were "catapulted" into action, seeking information about asthma from various sources and using that knowledge in asthma management.

Some of the fathers in this study relied on their wives to provide them with additional information about asthma. Because fathers' experiences have been examined so sparsely, it is not possible to draw any parallel from the literature to that finding. One does not know if that is typical of fathers in a married or cohabiting pair. Clark and Chalmers (2003) found that parents of children with asthma looked to family members for informational support, but fathers' perspectives were not singled out nor was there any direct reference to fathers relying on their spouses in that regard.

The fathers used the information and knowledge that they gained to carry out the tasks of asthma management. They learned about their children's medications and how to use them effectively to treat and sometimes to prevent asthma symptoms. They expended considerable effort in making adherence to the medication regime a part of everyday family life. Similar findings were reported by Horner (1998) who described how the parents in her study moved through a learning phase during which they mastered the basic tasks of asthma management. She identified "coming to know medications" as one of the major basic tasks parents had to master. Other studies made reference to parents mastering the medication regime as they moved through the process of adjusting to childhood asthma. For instance, Jerrett and Costello (1996) described the "being involved" phase during which parents learned about their children's medications. Similarly, Clark and Chalmers (2003) described how learning to manage asthma involved learning about the medication regime until, eventually, parents became adept at adjusting 
the medications in relation to their children's specific needs. In two studies, mothers of children with asthma identified medication administration as one of the caregiving demands encountered in the management of childhood asthma (Brown et al., 1996; Wasilewski et al., 1988). Although no specific reference to learning about medications was made in those particular studies, the findings indicated that the medication regime was a time-consuming and preeminent part of asthma care.

The fathers learned that control of the environment was an important component of asthma management. They endeavored to control the home environment by making changes in their homes and daily routines in a number of ways. Other researchers described how parents modified their home environment as they learned about asthma management (Clark \& Chalmers, 2003; Horner, 1998; Jerrett \& Costello, 1996). The fathers in this study seemed to rise to the challenge of maintaining a trigger-free environment for their children. Some studies revealed that parents struggled with environmental controls as these controls resulted in extra work and sometimes conflicted with existing lifestyles (Barrett et al., 2001; Brown et al., 1996; Wasilewski et al., 1988). However, the fathers in this study made a commitment to environmental control that was evident and they did whatever they could, and whatever was in their means, to improve the home environment for their children.

For the fathers in this study, learning about asthma management involved a blend of information and experience. As well as learning from the information and other education they obtained, the fathers learned by becoming familiar with their own children's asthma and participating in their care. Parents in other studies have identified the importance of experience in their learning about asthma management (Clark \& 
Chalmers, 2003; Jerrett \& Costello, 1996). For example, the parents in the Jerrett and Costello study described how they "learned a lot" on their own "from experience".

Overall, learning the ropes captured the fathers' accounts of gaining the knowledge and skills that enabled them to manage their children's asthma in an effective manner. Having good information about asthma and the necessary support for learning is essential to asthma management. Parents need to be able to access information from health care professionals as well as from other appropriate sources. However, learning about asthma management involves more than information gathering. It also involves an experiential component whereby parents apply their knowledge and, in doing so, further develop the attributes and skills that are necessary to competently manage their children's ongoing asthma care. The ability of parents to function independently in making decisions about the child's asthma care is essential due to the varying nature of the condition.

\section{Living With Concern}

The fathers in this study had a number of concerns in relation to their children's asthma. This is not a surprising finding. When parents are faced with childhood chronic illness, regardless of their knowledge and efforts to be compliant with treatment, there will be unknowns, especially about the future trajectory and management of the illness. It seems only natural that parents have concerns about a condition such as asthma which is associated with episodic symptoms, acute exacerbations of varying severity, the need for medications with inherent adverse effects, and the need for diligent management. Thus, along with the day-to-day parenting and illness care, parents have to deal with ongoing concerns about their children's chronic condition. 
In the current study, the fathers had concerns about their children's prescribed medications, safekeeping at school and overall well-being. In particular, they were concerned about the possible long-term effects of asthma medications, especially corticosteroids. Parents in other studies have reported concern about the long-term effects of their children's asthma medications (Kieckhefer \& Ratcliffe, 2000; Syndor-Greenberg \& Dokken, 2000) and have wondered about possible negative effects that corticosteroids might have on their children's physical development (Englund et al., 2001; SyndorGreenberg \& Dokken).

Most of the fathers' concern with their children's safekeeping at school was related to restrictive school policies that prevented the children from carrying medication with them. Concern about restrictive school policies regarding the use of medication also was reported by Barrett et al. (2001). Similar to the fathers in this study, the parents in that study described how they had experienced problems with their children's school because school regulations prevented children from carrying medication with them and that meant the children did not have easy access to their inhalers if they needed them in a hurry. The fathers in this study also worried about the possibility of their children being exposed to indoor and outdoor asthma triggers at school. Horner (1998) found that the parents in her study were cognizant of potential triggers in the school setting and took measures to promote a safe environment for their children at school.

The fathers in this study worried about their children's ongoing and future wellbeing. At times, they worried about whether the asthma might become more severe in the future. Parents in other studies also have expressed uncertainty about their children's future health, and have wondered about whether the child's asthma would become more 
severe or whether it would cause the child to live a limited life (Englund et al., 2001; Syndor-Greenberg \& Dokken, 2000; Whyte et al., 1995). The fathers' concern about the children's ability to manage the asthma on their own when they are older is consistent with findings by Syndor-Greenberg and Dokken. Those authors reported that parents worried about how their children would handle asthma management on their own when they are older and were cognizant of encouraging positive behaviors in their children in that regard.

Although the theme of uncertainty, prominent in other studies of parents of children with asthma (Horner, 1997; Jerrett \& Costello, 1996; Kieckhefer \& Ratcliffe, 2000; MacDonald, 1996; Whyte et al., 1995), was not identified in this study, some of the fathers' concerns, particularly regarding the course and progression of the illness, the children's future health, and the children's management of their asthma on their own when they are older, may be regarded as reflecting uncertainty.

\section{Being Vigilant}

The fathers in this study kept a watchful eye over their children. Vigilance became a routine part of the children's care, even when the asthma essentially was under control. In addition to being watchful for asthma symptoms, the fathers were alert to situations and environmental factors, both inside and outside the home, that might expose their children to asthma triggers. Similarly, Horner (1998) found that parents became proficient at recognizing and preventing asthma episodes by being on alert for precursor symptoms and possible trigger events. Englund et al. (2001) found that being the parent of a child with asthma involved vigilance. However, in that study it was mothers, and not fathers, who reported actions related to vigilance. There were further references in the 
literature that implied parental vigilance in the care of childhood asthma. For example, parents have reported that they had to monitor and pay attention to their children's asthma symptoms (Wasilewski et al., 1988; Brown et al., 1996), and in doing so became adept at predicting and preventing trigger situations (Clark \& Chalmers, 2003).

Although the fathers were vigilant and wanted to shield their children from situations that could exacerbate their asthma, they were cognizant of not overprotecting them. They encouraged their children to participate in the usual childhood activities. Similar findings were reported by Englund et al. (2001) in that fathers tried to liberate their children from the disease and believed that the children could live a normal life with asthma. As well, Horner (1998) concluded that the parents in her study adhered to a normalizing parenting style and supported their children's involvement in the normal activities of childhood.

Vigilance is a necessary component of asthma management. In order for parents to achieve effective asthma management it is necessary for them to be watchful of their children's environment and daily well-being. At the same time, parents need to be cognizant that overprotective strategies may hinder normal growth and development in their children. As the fathers in this study indicated, it is necessary to achieve a good balance between maintaining prudent vigilance and allowing children to participate in normal childhood activities.

\section{Being Comfortable With Asthma Management}

The fathers in this study had learned how to manage their children's asthma. Achieving effective management allowed asthma to be moved from being the central focus of the family's attention to being just another part of everyday family life. Despite 
the extra demands and responsibilities inherent in caring for a child with asthma, and the concern about their children's health and well-being, the fathers did adjust and successfully incorporated asthma management into their daily lives. They expressed confidence and felt capable, and reflected on the factors that enabled them, over time, to be comfortable with asthma care.

All of the fathers recognized the value of asthma education, both formal and informal, in the management of their children's asthma. Knowledge about asthma and the rationale for the treatment plan provided the fathers with the foundation to carry out the activities required for their children's care. In previous studies, asthma education was found to have a positive influence on parental adaptation to the condition (Colland, 1993; Deaves, 1993), self-efficacy in managing childhood asthma (Hanson, 1998), confidence in asthma management (Deaves), and sense of control and ability to make decisions about asthma care (McCarthy et al., 2002).

The fathers' comfort level with asthma management increased as they gained experience with managing their own child's asthma. The parents in another study also acknowledged the value of experiential learning (Jerrett \& Costello, 1996). In that study, the parents described how experience in managing their own child's asthma was important to gaining control of it. It helped them to develop confidence and act independently in making decisions about their children's care.

The fathers' feelings of confidence were further reinforced as they saw their children respond positively to the treatment plan and become healthier than they had been prior to treatment. Clark and Chalmers (2003) also noted that satisfaction with their 
children's level of health was an important factor in helping parents to successfully incorporate asthma care into their daily lives.

The fathers felt fortunate to have supportive relationships with their spouses, extended family members, and friends. Parents in other studies also have identified social support as important to adjustment to their children's illness situation. Wasilewski et al. (1988) reported that the mothers in their study viewed fathers who participated in their children's asthma care as providing valuable support. Clark and Chalmers (2003) found that parents' perception of support from family and friends was a primary factor that influenced their successful movement through the process of learning about asthma management. The support that the parents in that study received included direct help, emotional support, and informational support. Other researchers highlighted the importance of support systems by referring to situations in which support systems were either deficient or weak. For example, Mailick et al. (1994) suggested that in the absence of adequate support systems, caregivers of children with asthma experienced personal strain. As well, Peri et al. (1991) noted that when spouses disagreed about aspects of their children's treatment plan, it led to disharmony between them, and that disharmony was one of the most disturbing elements of the illness situation for them.

The fathers in this study had good relationships with the health care providers and felt a sense of partnership with them. They felt that their children were being well attended to. The importance of supportive health care professionals in assisting parents to become effective managers of their children's asthma was discussed in other studies (Clark \& Chalmers, 2003; Jerrett \& Costello, 1996). In both studies, parents derived comfort from the support they received from the professionals who were involved in their 
children's asthma care, and they viewed that support as an important factor in helping them to gain control of asthma management. As well, McCarthy et al. (2002) noted that an empowering approach to asthma education, which encouraged parents to work in partnership with professionals, resulted in an increased sense of control for parents and an increased ability to provide asthma care.

The fathers in this study portrayed an overall attitude of acceptance towards their situation. They felt that fatherhood entailed numerous responsibilities and now that their children had asthma, managing it effectively was just another such responsibility. They seemed to direct their energies towards accomplishing the task at hand and moving forward. They were able to see positive aspects of their situation and, despite having concerns about their children, they had some hope and optimism for the future. Englund et al. (2001) noted a similar finding. The fathers in their study expressed feelings of acceptance toward their situation. They felt hope for the future and had faith that treatment for asthma would improve, with the result that their children would live normal lives.

A substantial portion of the literature concerning parents and childhood asthma revealed that parents of children with asthma experienced stress in their lives due to the presence of the illness in their children. Surprisingly, the fathers in this study made no reference to actual stress in relation to their children's illness or care. During the prediagnosis period, the fathers indicated that they were concerned about the recurrent illness episodes that their children had been experiencing. However, they focussed more on the relief that they felt with knowing the diagnosis rather than the concern that they had felt earlier. Although the tasks associated with asthma management added to their 
parental responsibilities, the fathers in this study did not dwell on the negative aspects of the caregiving experience.

There are a number of possible reasons for the difference in findings between the literature and this current study. The majority of participants in previous relevant research were mothers. It may be that the experience of mothers is different than that of fathers in the context of having a child with asthma. Mothers may feel they shoulder the responsibility for the care of their children with asthma and, therefore, feel stressed and burdened by the demands of the caregiving experience. Indeed, in one previous study mothers did feel that they were responsible for the bulk of their children's asthma care (Englund et al., 2001). In a number of studies, mothers indicated that, in being responsible for their children's asthma care, they incurred a number of caregiving demands such as: handling an asthma episode, and managing discipline and behavioral problems (Svavarsdottir et al., 2000); administering medications, monitoring for asthma symptoms, and maintaining environmental controls (Brown et al., 1996; Wasilewski et al., 1988); providing emotional support to the child during symptomatic periods (Wasilewski et al.); and coordinating asthma management with teachers, day care workers, and family members (Brown et al.). The demands of caregiving, in turn, had a negative effect on aspects of their functioning, such as: fatigue and interrupted sleep (MacDonald, 1996; Svavarsdottir et al.; Wasilewski et al.); and absences from work, and interruptions in social activities and family outings (Brown et al.; Wasilewski et al.). Another point to consider is that the fathers in this study had learned to manage their children's asthma in an effective manner and had successfully incorporated asthma management into everyday family life. It may be that in reflecting on their experiences 
from the standpoint of fathers who had accomplished the tasks of asthma management, they had discounted any stress that might have been associated with the experience, in particular, any stress during the early period of having a child with asthma. At the time the interviews were conducted with the fathers in this study, their children had been diagnosed for a period ranging from two to six years. At that time, they were at a point in their experience where they had mastered asthma management and were comfortable with their situation. Had the interviews been conducted at an earlier point in the children's asthma illness trajectory, for example, when they were newly diagnosed, the fathers may have recounted a different experience, that is, one in which they felt stress. Given the nature of phenomenological enquiry, the fathers were asked to relive their experience as they saw it and were not lead by the researcher. It is possible that a study in which specific questions were directed to participants about the stressors associated with being the father of a child with asthma might produce another perspective of their experience. 


\section{CHAPTER 6}

\section{IMPLICATIONS AND SUMMARY}

The very nature of phenomenological inquiry limits generalizability of the findings (van Manen, 1994). However, the findings of this study have provided insight into the lived experience of fathers who have children with asthma. Understanding another's experience is of primary importance in the provision of appropriate nursing care. Thus, even though it is not the intent of phenomenology to generalize results to the larger population, this study does have implications for nursing. In this chapter, implications for nursing practice, nursing education, and nursing research are discussed, followed by a brief summary of the study.

\section{Implications}

\section{Nursing Practice}

This study of fathers who have children with asthma has a number of implications for nurses working with this population of clients. Nurses need to take the time to understand the lived experience of fathers who have children with asthma. Understanding their experience and gaining insight into their needs and concerns is a first step to providing supportive nursing care. The nurse should be alert to fathers' verbal and nonverbal cues, and assist them in articulating their feelings, while recognizing that their needs, concerns, or worries may differ from those of mothers.

This study has highlighted the significance of asthma education in the experience of fathers who have children with asthma. Nurses need to be cognizant of the importance that fathers attach to learning about their children's asthma. The fathers in this study spent a lot of time learning about asthma and its management. They wanted information 
about asthma, both at the time of the diagnosis and on an ongoing basis. Therefore, it is important for nurses to provide opportunities for both formal and informal asthma education in all clinical settings. Nurses can play an important role both in imparting and clarifying information about the disease process, prescribed medications, medicationrelated issues, and the child's treatment plan. Nurses also can provide fathers with information on resources they can access for updated and accurate information about asthma and its management, such as appropriate Internet sites and the local lung association. Since some of the fathers' learning occurred as a result of participating in their children's asthma care, nurses should maximize opportunities to facilitate fathers' participation in their children's asthma management. When fathers are present in the clinical setting, they should be encouraged to perform aspects of their children's care and to participate in decisions about their children's treatment plans.

The fathers derived comfort and reassurance from the support of the practitioners they had encountered. Thus, it is important for nurses to be aware of the significant role that efficient, caring, and supportive health care providers can play in enabling fathers of children with asthma to adapt to and become comfortable with their children's illness situation. Nurses need to assess fathers' current levels of support and their perception of the adequacy of those supports. Fathers who see their support as inadequate (e.g., single fathers who do not have spousal support) could be helped to identify sources of support in their family and community. Since it was evident that the fathers in this study drew on support from people outside their family, it would be appropriate for the nurse to inform fathers about any existing support groups for families with childhood asthma. Where such a group does not exist, the nurse could facilitate the initiation of one, so as to 
provide an opportunity for fathers of children with asthma to meet and share their experiences. It has been suggested in the literature that fathers of children with chronic illness need avenues for men to talk with other men, whether it is within a group or oneto-one (May, 1996). Fathers may derive comfort from the realization that they are not alone, and that others have been there, too, and learned to cope.

Community health nurses, particularly school nurses, can play an advocacy role in assisting fathers to collaborate with the school system about their children's asthma care. Fathers and their families should be encouraged to maintain communication with their child's school nurse in that regard. School nurses could work with teachers and school personnel in developing informational materials, written guidelines and school policies with respect to asthma management in the school setting. As well, school nurses could conduct educational sessions about asthma for teachers who have students with asthma in their classes. Pediatric nurse practitioners, clinical nurse specialists, and nurse coordinators of asthma clinics in hospitals and other health care agencies could liaise with school nurses in developing effective partnerships with school personnel and school boards in developing school asthma policies that meet the needs of the child and family with asthma. Teachers and other school personnel need to understand the importance of children with asthma having ready access to inhalers or other emergency medications. Nurses could be proactive in encouraging educators to develop flexible medication policies that would allow children with asthma to carry such medications on their person. Nurses could also work with teachers and school personnel in developing guidelines and policies to promote a trigger-friendly environment that would enhance the comfort and safety of children with asthma while they are in the school setting. 


\section{Nursing Education}

Nurse educators have the responsibility to heighten nursing students' awareness of the impact that a childhood chronic illness, such as asthma, may have on the family unit. Educators who develop pediatric courses in basic nursing degree programs should ensure that content is included to address the role of the family and individual family members in the care of a child with a chronic illness. Attention should be placed on how the traditional role of the father in North American society has changed, with fathers now taking a more active role in caregiving. Nursing education curricula should be reflective of the supportive, facilitative, and informational roles that nurses can fulfill in their interactions with fathers who are caring for children with chronic illnesses like asthma. At the same time, nursing students need to be aware of the fact that each society has its norms and expectations for fathers. Therefore, nursing curricula should include comparisons among different cultures of fathers' functioning within the family context.

Students need to understand that, although there are broad concepts that are related to the care of a child with a chronic illness, there are management issues that are specific to individual illnesses. Given that asthma is the most common chronic illness of childhood (ALA, 2003; CLA, 2003), future nurses who will be working with the pediatric population need to be knowledgeable about childhood asthma in order that those children and their families receive quality care. Nurse educators need to encourage students to be sensitive to the needs and concerns of fathers, and encourage them to facilitate fathers' participation in their children's care. Students need to be encouraged to explore with fathers what they are experiencing as a result of being the father of a child with asthma. Student sensitivity to fathers in the clinical setting also may be increased by asking 
students to read about and discuss findings of research related to fathers. For example, the findings from this study furnished insight into what the experience was like for fathers and could be useful for students as they encounter fathers in the clinical setting.

Nurses play key educative and supportive roles as they work with asthmatic children and their parents in inpatient and outpatient settings, emergency departments, and community settings. As research reveals new insights into the perspective of fathers who have children with asthma, these insights need to be communicated to nurses working in those areas. Asthma educators could conduct periodic information sessions and seminars concerning childhood asthma, and ensure that current research related to the father's perspective is included in the educational program. Fathers of children with asthma could be asked to participate in such programs and discuss their personal experience with being the father of a child with asthma. Those fathers could act as valuable resources in helping nurses and other health care professionals understand what it is like to be the father of a child with asthma.

\section{Nursing Research}

Additional qualitative research into the lived experience of fathers who have children with asthma is needed to determine if participants from other cultural, socioeconomic, and educational backgrounds describe similar lived experiences. The fathers in this study lived in an urban area where health care services and resource people were readily accessible. Research exploring the experience of fathers who live in rural areas would also be valuable as their experience may be different from that of urban fathers. Since only married fathers were participants in this study, further research could include single fathers, divorced fathers, and fathers who are not living with their children. 
This study investigated the experiences of fathers of children with asthma who were between the ages of 6 and 11 years. Studies investigating the experience from the perspective of fathers of preschool and adolescent children also would be valuable. As well, future research to investigate the experience of fathers with children who have severe asthma or asthma that is not well controlled with medications and environmental measures could highlight the impact that those factors have on fathers' experience.

The fathers in this study relied on a number of supports to help them with their children's asthma management. Further research into the type of support that fathers seek and find helpful would provide nurses with a greater understanding of what potential resources fathers might draw upon when providing care to their children. The fact that fathers in this study had a need for information about asthma points to the necessity for research that explores fathers' opinions of the means by which they can be given appropriate types of informational support.

Since there is very little in the literature about fathers' perspectives in relation to childhood asthma, it would be valuable to conduct further research to explore their situation more fully. Future qualitative and quantitative studies should explore specific aspects of fathers' adaptation and adjustment to the illness situation, and determine their unique needs and coping mechanisms. As well, more research should be conducted that compares and contrasts the experiences of mothers and fathers who have children with asthma to determine similarities and differences.

The fathers in this study described problems that they experienced with respect to their children's safe-keeping while at school. There was a clash between school requirements, particularly in regard to medication policies, and the children's needs in 
relation to their asthma. Given that, throughout childhood, children spend a substantial amount of time in the school setting, there is a need to develop school policies that support the health and safe-keeping of children with asthma. Research is needed to determine effective processes for developing and implementing generalizable school policies in relation to asthma care, as well as methods for evaluation of such policies. The findings from this study also suggest that parents' experience in relation to having a child with asthma at school could be further explored. As well, research to explore the concerns and resource needs of teachers with respect to childhood asthma in the school setting would be beneficial to the overall care of children with asthma and their families.

\section{Summary}

A literature review revealed that there was a gap in the existing body of knowledge regarding fathers and childhood asthma. This phenomenological study was undertaken to explore the lived experience of fathers who have children with asthma. The study was conducted using van Manen's (1994) mode of inquiry. In-depth interviews were carried out with eight fathers of children with asthma. Analysis of the interviews revealed five themes: feeling relief in knowing the diagnosis, learning the ropes, living with concern, being vigilant, and being comfortable with asthma management.

Findings from this study provide support for findings in previous studies where parents' experiences with childhood asthma had been explored. This study contributes to the existing body of knowledge related to parents and childhood asthma, and provides new insight into the paternal experience. The findings have implications for nursing practice, education and research. It is important to include fathers in future research studies and examine their unique experience in parenting ill children. 


\section{REFERENCES}

American Lung Association. (2003). National health interview survey. Retrieved June 10, 2003, from www.lungusa.org/data/data_102000.html

Barrett, J. C., Gallien, E., Dunkin, J., \& Ryan, L. (2001). Managing asthma within the context of the rural family. Public Health Nursing, 18, 385-391.

Beck, C. (1993). Quantitative research: The evaluation of its credibility, fittingness, and audibility. Western Journal of Nursing Research, 15, 263-266.

Brown, J. V., Avery, E., Mobley, C. Bocuti, L., \& Golbach, T. (1996). Asthma management by preschool children and their families: A developmental framework. Journal of Asthma, 33, 299-311.

Bussing, R., \& Burkett, R. (1993). Anxiety and intrafamilial stress in children with hemophilia after the HIV crisis. American Academy of Child and Adolescent Psychiatry, 32, 562-567.

Canadian Asthma Consensus Group. (1999). Canadian asthma consensus report. Canadian Medical Association Journal, 161(11, Suppl.), S1-S12.

Canadian Asthma Consensus Group. (2001). Asthma Guidelines Update 2001. Canadian Respiratory Journal, 8 (Suppl.A), 5A-27A.

Canadian Lung Association. (2003). Asthma. Retrieved June 1, 2003, from http://www.lung.ca/asthma/asthmal.html

Clark, B. A., \& Chalmers, K. I. (2003). Childhood asthma: Helping parents cope. Canadian Nurse, 99 (2), 19-22.

Colland, V. T. (1993). Learning to cope with asthma: A behavioural self-management program for children. Patient Education and Counseling, 22, 141-152.

Conners, C., \& Millar, W. J. (1999). Changes in children's hospital use. Health Reports, 11(2), 9-19.

Deaves, D. M. (1993). An assessment of the value of health education in the prevention of childhood asthma. Journal of Advanced Nursing, 18, 354-363.

Donnelly, K. (1994). Parents of children with asthma: An examination of family hardiness, family stressors, and family functioning. Journal of Pediatric Nursing, $6,398-408$. 
Eiser, C., Eiser, J. R., Town, C., \& Tripp, J. H. (1991). Discipline strategies and parental perceptions of preschool children with asthma. British Journal of Medical Psychology, 64, 45-53.

Englund, A. D., Rydstrom, I., \& Norberg, A. (2001). Being the parent of a child with asthma. Pediatric Nursing, 27, 365-373.

Graves, V. E. (1997). Families and children's chronic conditions: Knowledge development and methodological considerations. Scholarly Inquiry for Nursing Practice: An International Journal, 11, 259-290.

Hamlett, K. W., Pellegrini, D. S., \& Katz, K. S. (1992). Childhood chronic illness as a family stressor. Journal of Pediatric Psychology, 17 (1), 33-47.

Hanson, J. (1998). Parental self-efficacy and asthma self-management skills. Journal of the Society of Pediatric Nurses, 3(4), 146-154.

Health Canada. (2001). Respiratory disease in Canada. Ottawa: Author.

Horner, S. D. (1997). Uncertainty in mothers' care for their ill children. Journal of Advanced Nursing, 26, 658-663.

Horner, S. D. (1998). Catching the asthma: Family care for school-aged children with asthma. Journal of Pediatric Nursing, 13, 356-366.

Jerrett, M. P., \& Costello, E. A. (1996). Gaining control: Parents experiences of accommodating children's asthma. Clinical Nursing Research, 5, 294-308.

Kieckhefer, G. M., \& Ratcliffe, M. (2000). What parents of children with asthma tell us. Journal of Pediatric Health Care, 14, 122-126.

Krefting, L. (1991). Rigor in qualitative research: The assessment of trustworthiness. American Journal of Occupational Therapy, 45, 214-222.

Kurnat, E. L., \& Moore, C. M. (1999). The impact of a chronic condition on the families of children with asthma. Pediatric Nursing 25, 288-292.

MacDonald, H. (1996). "Mastering uncertainty": Mothering the child with asthma. Pediatric Nursing, 22, 55-59.

Mailick, M. D., Holden, G., \& Walther, V. N. (1994). Coping with childhood asthma: Caretakers views. Health \& Social Work, 19, 103-111.

May, J. (1996). Fathers: The forgotten parent. Pediatric Nursing, 3, 243-246, 271. 
McCarthy, M. J., Herbert, R., Brimacombe, M., Hansen, J., Wong, D., \& Zelman, M. (2002). Empowering parents through asthma education. Pediatric Nursing, 28, 465-473.

Millar, W. J. \& Hill, G. B. (1998). Childhood asthma. Health Reports, 10 (3), 9-21.

Newby, N. M. (1996). Chronic illness and the family life cycle. Journal of Advanced Nursing, 4, 786-791.

National Institutes of Health. (2002). Global initiative for asthma: Global strategy for asthma management and prevention NHLBI/WHO workshop report. Retrieved June 13, 2002, from htpp://www.ginasthma.com

Peri, G., Molinari, E., \& Taverna, A. (1991). Parental perceptions of childhood illness. Journal of Asthma, 28, 91-101.

Speziale, H. J., \& Carpenter, D. (2003). Qualitative research in nursing: Advancing the humanistic imperative (3rd ed.). Philadelphia: Lippincott.

Statistics Canada. (1999). National population health survey, 1998/99. Ottawa: Author.

Staudenmayer, H. (1981). Parental anxiety and other psychosocial factors associated with childhood asthma. Journal of Chronic Diseases, 34, 627-636.

Svavarsdottir, E. K., McCubbin, M. A., \& Kane, J. H. (2000). Well-being of parents of young children with asthma. Research in Nursing \& Health, 23, 346-358.

Syndor-Greenberg, N., \& Dokken, D. (2000). Communicating information at diagnosis: Helping families and children manage asthma. Journal of Child and Family Nursing, 3, 290-295.

The National Asthma Control Task Force. (2000). The prevention and management of asthma in Canada: A major challenge now and in the future. Ottawa: Health Canada.

Tiedje, L. B., \& Darling-Fisher, C. G. (1996). Fatherhood reconsidered: A critical review. Research in Nursing and Health, 19, 471-484.

van Manen, M. (1994). Researching lived experience: Human science for an action sensitive pedagogy. London, ON: Althouse Press.

Wasilewski, Y., Clarke, C., Evans, D., Feldman, C. H., Kaplan, D., Rips, J., \& Mellins, R. B. (1988). The effect of paternal social support on maternal disruption caused by childhood asthma. Journal of Community Health, 13(1), 33-42. 
Whyte, D. A., Baggaley, S., \& Rutter, C. (1995). Chronic illness in childhood: A comparative study of family support across four diagnostic groups.

Physiotherapy, 81, 515-520. 
APPENDIX A 


\section{Interview Guide}

The interview will be introduced by telling the participant of the researcher's interest in his thoughts, feelings, or concerns as the father of a child with asthma. The researcher will state: "I understand you have a daughter/son who has asthma. I would like for you to tell me about your experience as the father of a child with asthma." The participant will be encouraged to talk about anything that will help the researcher to understand his experience

The following questions will be used during the interview as a guide to data collection. Prompts such as "Can you tell me more about that?", which are clarifying, but not leading, may also be used.

1. What does it mean to you to be the father of a child with asthma?

2. Describe how you felt when your child was first diagnosed with asthma.

3. Describe how you feel now. Have you gone through a period of adjustment?

4. How has having a child with asthma affected your life? For example, have changes in your life been necessary?

5. Are there things about being the father of a child with asthma that bother you or are difficult for you? What do you find most difficult about being the father of a child with asthma?

6. Are there positive things that have resulted from being the father of a child with asthma?

7. What things have you found to be most beneficial in helping you care for your child?

8. What did you have to do in order to learn how to care for your child's asthma?

9. Whom have you found to be most supportive in helping you care for your child?

10. Have you accessed any community resources to help you care for your child's asthma? Do you feel that there are sufficient available resources to help you care for your child?

11. Has the asthma changed your interactions within the family; with your child, with your other children or with your spouse?

12. What information have you received about asthma? Are you satisfied with the information you have received?

13. How would you describe your overall satisfaction with the care your child has received?

14. Is there anything else you would like to tell me about your experience in being the father of a child with asthma? 
APPENDIX B 


\section{HealthCare \\ Corporation of St. John's}

January 17,2000

Ms. G. Cashin

Centre for Nursing Studies

Southcott Hall

Dear Ms. Cashin:

Your research proposal HIC 99.161 - The Lived Experience of Fathers who have Children with Asthma: A Phenomenological Study was reviewed by the Research Proposals Approval Committee (RPAC) of the Health Care Corporation of St. John's at its meeting on January 11,2000 , and we are pleased to inform you that the proposal has been approved.

This approval is based on the understanding that it has the necessary funding and that it is being conducted at the Janeway site only. Additionally, the Committee requires a progress report to be submitted annually.

If you have any questions or comments, please contact Lynn Purchase, Manager of the Patient Research Centre, at 737-7283.

Sincerely,

Pamela Elliott

Vice President

Patient Care Services

$\mathrm{mh}$

c Ms. Lynn Purchase

Manager

Patient Research Centre

\section{General Hospital}

300 Prince Philip Drive, St. John's, Newfoundland, Canada A1B 3V6 Tel. (709)737-6300 Fax (709)737-6400 
APPENDIX C 


\section{Participant Profile}

Code Number

Date and Place of 1st Interview

Date and Place of 2nd Interview

Age of Father

Current Marital Status

Occupation at Present

Education Level (number of years)

Number of Children in Family

Number of Children with Asthma

Age, Gender, \& Position in Family of Child/Children with Asthma

(1) Age

Gender

Position in Family
(2) Age

Gender

Position in Family

How would you rate the severity of your child /children's asthma?

(1) Mild

Moderate

Severe
(2) Mild

Moderate

Severe 
APPENDIX D 
University of Newfoundland

Office of Research and Graduate Studies (Medicine)

Faculty of Medicine

The Health Sciences Centre

19991201

TO: Ms. G. Cashin

FROM: $\quad$ Dr. F. Moody-Corbett, Assistant Dean

Research \& Graduate Studies (Medicine)

SUBJECT: Application to the Human Investigation Committee - \#99.161

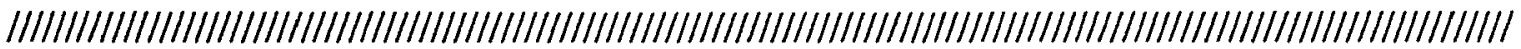

The Human Investigation Committee of the Faculty of Medicine has reviewed your proposal for the study entitled "The Lived Experience of Fathers Who Have Children with Asthma: A Phenomenological Study".

Full approval has been granted for one year, from point of view of ethics as defined in the terms of reference of this Faculty Committee.

For a hospital-based study, it is your responsibility to seek necessary approval from the Health Care Corporation of St. John's.

Notwithstanding the approval of the HIC, the primary responsibility for the ethical conduct of the investigation remains with you.

$\frac{2}{7}$

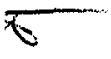

F. Moody-Corbett, $\mathrm{PhD}$

Assistant Dean

cc: $\quad$ Dr. K.M.W. Keough, Vice-President (Research)

Dr. R. Williams, Vice-President, Medical Services, HCC

Ms. Sandra Small, Supervisor 
APPENDIX E 


\section{Consent to Participate in a Nursing Research Study}

TITLE: The Experience of Fathers Who Have Children with Asthma.

INVESTIGATOR: Geraldine Cashin, B.N., R.N.

Master of Nursing Student

School of Nursing, Memorial University of Newfoundland

St. John's, NF

A1B 3V6

You have been asked to participate in a research study. Participation in this study is entirely voluntary. You may decide not to participate or may withdraw from the study at any time without any affect to the care or services you or your child receive. Further, you may refuse to answer any specific questions.

Information obtained from you or about you during this study which may be identifying will be kept confidential by the investigator. Your name will not be recorded with any of your responses to the questions, nor will it be identified in any discussion or written report of the study findings. The investigator will be available during the study should you have any concerns or questions about the study.

Purpose of the Study: The purpose of this study is to explore and describe the experience of being the father of a child with asthma. Asthma is the most common chronic illness of childhood. It is the leading cause of school absenteeism and is responsible for a large number of pediatric admissions to emergency departments and hospitals. When a child is diagnosed with asthma, the parents become responsible for the long-term home management of the condition. Relief of the child's symptoms is an important aspect of asthma care. However, promoting family well-being cannot be overlooked. There is some information available on mothers' needs and experiences related to having a child with asthma. However, fathers' needs and experiences have not been determined. With fathers sharing in the child care role, a greater understanding of their experience is essential. The information that you provide may help nurses and other health care workers better understand the needs and concerns of fathers who have children with asthma.

Duration of Participation: The study involves two interviews; the first will last approximately one hour and the second will last from 20 to 45 minutes. It is expected the second interview will occur within two months of the first interview.

Participant's Initials 
Description of Procedure: During the first interview, you will be asked to talk about your thoughts, feelings and concerns as the father of a child with asthma. You will be asked questions which should help you to describe your experience. The purpose of the second interview is to have you clarify information provided during the first interview, if necessary, and confirm my interpretation of the information. Both interviews will be audiotaped, with your permission. The tapes will be erased when the study is completed. At the end of the first interview, you will be asked questions concerning personal information including your age, marital status, occupation, educational level, and the age, gender and position in the family of the child (children) with asthma.

Foreseeable Risks, Discomforts or Inconveniences: There are no expected risks from participating in this study. Participating in the interviews may be an inconvenience for you. The interviews will be scheduled at a time and place that is suitable for you.

Benefits Which May Be Received: Having an opportunity to share your experience as a father of a child with asthma is the only benefit which you may derive.

A copy of the final report will be available to you upon request to Geraldine Cashin, School of Nursing, Memorial University of Newfoundland, St. John's, NF, A1B 3V6, Telephone (709) 737-6695.

If you have any questions about this study you may address them to Geraldine Cashin at (709) 722-0541. If you have any questions concerning your rights as a research participant, you may address them to the Human Investigations Committee, Memorial University of Newfoundland at (709) 737-6974.

Your signature on this form indicates that you have understood to your satisfaction the information regarding your participation in this research project and that you agree to participate. In no way does this waive your legal rights nor release the investigator from her legal and professional responsibilities.

I, in the research study. , the undersigned, agree to my participation 
Any questions have been answered and I understand what is involved in the study. I further understand that the interviews will be audiotaped. I realize that participation is voluntary and that there is no guarantee I will benefit from my involvement. I acknowledge that a copy of this form has been given to me.

Signature of Participant

Date

$\underline{\text { Investigator }}$

To the best of my ability I have fully explained to the participant the nature of this research study. I have invited questions and provided answers. I believe that the participant fully understands the implications and voluntary nature of the study. 



